\title{
Sovereign Risk Zones in Europe During and After the Debt Crisis
}

(Received 00 Month 20XX; in final form 00 Month 20XX)

\begin{abstract}
We employ a machine learning approach to build a European sovereign risk stratification using macroeconomic fundamentals and contagion measures, proxied by copula-based credit default swap (CDS) dependencies over the period 2008-2017, for France, Germany, Greece, Ireland, Italy, Portugal, and Spain. By adopting a recursive partitioning strategy we detect specific risk zones varying from safe to high risk based on key predictors, and we construct their specification by assigning specific risk thresholds. While key macroeconomic fundamentals such as Debt/GDP and the unemployment rate remained the same and maintained the same risk thresholds during the sub-periods 2008-2013 and 2013-2017, the CDS spreads contagion dropped significantly over the post-Quantitative Easing years, lowering the corresponding risk thresholds. We estimate an impact on CDS spreads approximately of -105 basis points in the period 2013-2017 due to contagion mitigation.
\end{abstract}

Keywords: contagion, copula, credit default swaps, machine learning, regression trees, systemic risk. JEL classification: C11, G01, G10.

\section{Introduction}

On April 26, 2010, three days after the Greek prime minister asked the European Union and the International Monetary Fund for financial help, the Greek 5-yr sovereign credit default swap (CDS) reached the 700 basis points (hereafter, bps), giving rise to similar dynamics for the CDS spreads of Italy, Spain, Portugal, and Ireland. During that period, and more specifically from 2010 to 2012, the price of sovereign credit risk in Europe has been increasingly affected by contagion effects. Afterwards, on July 26, 2012, Mario Draghi announced to do "whatever it takes" to preserve the Euro, and the resulting Outright Monetary Transactions (OMT) Program led to a significant reduction in the sovereign yields of periphery countries. Low yields on sovereign bonds have continued to characterize the post-crisis thanks to Quantitative Easing (QE) interventions and macro-prudential policy measures, but since the end of the second half of 2016 capital markets appeared prone to volatility, with long-term rates being on the rise (DeGrauwe et al. (2017)). Fig 1 reports the 5-yr sovereign CDS spreads of the above mentioned Euro countries also indicating the major events occurred over the period from January 2008 to May 2017.

We would like to thank Pierluigi Balduzzi, Andreas Pick and the participants of Consortium for Systemic Risk Meeting Analytics Semi-Annual Meeting (2014) held at the Massachusetts Institute of Technology in Cambridge, Massachusetts, the SYRTO Conference on Systemic Risk, organised by the Finance and Econometrics departments of the VU University Amsterdam and held in Amsterdam on June 4-5, 2015, the SYRTO Final International Conference, organized by the Université Paris 1 Panthéon, Sorbonne, and held in Paris on February 2016, the 2016 RiskLab/BoF/ESRB Conference on Systemic Risk Analytics held in Helsinki for their beneficiary comments. The last three authors acknowledge funding from the European Union's Seventh Framework Programme (FP7-SSH/2007-2013) for research,technological development and demonstration under grant agreement no. 320270-SYRTO. 
What is the link between the price of sovereign risk and the macroeconomic fundamentals during the Euro sovereign debt crisis? The topic attracted a great deal of attention in the financial literature leading to three key features.

Point 1: From 2010 the price of sovereign risk became extremely sensitive to macroeconomic fundamentals also showing significant co-movements over time (see, for example, De Santis (2014), Beetsma et al. (2013), Longstaff et al. (2011), Kalbaskaa and Gatkowski (2012), Aizenman et al. (2013), Beirne and Fratzscher (2013), Broto and Perez-Quiros (2015), Caporin et al. (2018), Mink and de Haan (2013)). Moreover, spillover effects and feedback loop between European debt crisis and the financial sector have been pervasive (Acharya et al. (2010), Alter and Schuler (2012), DeBruyckerea et al. (2013)).

Point 2: Sovereign risk has a systemic nature. Reboredo and Ugolini (2015) provide evidence that while the systemic impact of the Greek debt crisis is not so severe for non-crisis countries, systemic risk instead increases for countries in crisis. Ang and Longstaff (2013) find strong heterogeneity among US and European issuers in their sensitivity to systemic risk and considerable evidence on the key role assumed by financial market variables.

Point 3: Sovereign risk dynamics exhibit changes in regimes over time. Caceres et al. $(2010)$ show that during the early period of the crisis the main cause was risk aversion, while in the later stages country-specific factors such as public debt and budget deficit played a primary role in the sharp rise in sovereign spreads. Arghyrou and Kontonikas (2012) find evidence confirming changes in the regime for sovereign debt pricing with a dominant role assumed by country-specific macro-fundamentals during the crisis. Ait-Sahalia et al. (2014) capture the dependencies among Eurozone CDS spreads proving the existence of clusters in time and space. Stamatopoulos et al. (2017) find a structural break around early 2011 in the estimated pattern of the CDS between pre(2008-2010) and post- (2011-2013) crisis periods: during pre-crisis period the downgrade ratings effects have prevailed, whereas in the post-crisis one the key role was played by country-specific macro-fundamentals (debt). Our research hypothesis is that sovereign risks are affected by both between-countries financial contagions and country-specific fundamentals. We use CDS spreads and ordinal associations as sovereign risk and contagion proxies respectively. Our objective is to enrich our understanding of sovereign risk variability by including financial contagions that may explain behaviors within and without a financial crisis. We embrace an algorithmic modeling culture based on machine learning through which, in the words of Breiman (2001b), the data are processed trying to speak about sovereign risk. Thus, we do not employ calibrating models that start from equilibrium beliefs such as minimising representative agents. The historical interplay between economic theory and empirical models has been often discussed in the literature; see, for example, Pesaran and Smith (1995), Mullainathan and Spiess (2017), Athey (2018). We do not position ourselves to any of the schools of thought in this area but we emphasize that empirical work may provide useful insights to theoretical developments and as such our findings suggest an ex-post theory. What we learned from the Euro sovereign debt crisis is that to get information about the underlying sovereign risk dynamics we need to fully understand the complex, nonlinear, time-varying and multidimensional nature of the data. We prove that a machine learning approach in the form of a non-parametric model combination as the one proposed in this paper makes more accurate data-driven predictions than standard data models, thus providing better and more information about the underlying sovereign risk mechanism. A key aspect of our approach is that we employ nonparametric statistical modeling tools with inferential procedures based on ensemble learning. Specifically, after measuring financial contagion in CDS through copula functions, we inspect how these proxies together with country-specific fundamentals affect CDS spreads by employing regression trees analysis. The procedure approximates the sovereign risk dynamics as a set of piecewise linear functions, where observations are grouped through multidimensional data splits. In other terms, we stratify the sovereign risk in some "risk zones" based on a small set of predictors, which are combined together using specific risk thresholds. These values act as "red flags" providing valuable early warning signals to countries that are moving towards dangerous risk paths. 
Moreover, to assess the importance of the leading indicators used to explain the dynamics of the sovereign CDS we also adopt the random forest procedure, which is essentially a collection of regression trees using different combinations of variables and samples.

The novelty of our approach is therefore in strengthening inferences by combining a number of statistical models (copula, regression trees, random forest), rather than just one, with the end of learning from and make predictions on sovereign risk expressed in terms of CDS spreads.

As in Rodriguez (2007), contagion in CDS dynamics is computed using copula approach, which allows dealing with nonlinear, time-varying dependence structures. The meaning we attribute to contagion is in line with Forbes and Rigobon (2002), who define it as the cross-market linkages after a shock to a country (or group of countries) which is translated into correlation breakdowns. As noted by Rodriguez (2007), the changes in dependence structures during periods of financial turmoil are an important dimension of contagion, and copulas are well suited to capture such periods. In our study, we employ a rich Bayesian model averaging strategy in which various copula specifications that are allowed to change in time produce a nonlinear dependency measurement expressed as a posterior mean of Kendall's $\tau$. The time changing process of copula specifications is based on thresholds which have a priori unknown locations and number. The resulting measures are therefore highly nonlinear, as they are produced as averages across models with different copulas, number of thresholds and threshold locations. The inference is achieved through a populationbased, reversible-jump Markon Chain Monte Carlo (MCMC) algorithm.

The sample used in our analysis refers to daily quotes of the 5-yr sovereign CDS spreads and macroeconomic country-specific indicators for Greece, Ireland, Italy, Portugal and Spain (hereafter GIIPS), France and Germany over the period from $01 / 02 / 2008$ to $05 / 23 / 201$ 证. Additionally, we use sovereign, financial and banking US CDS spreads, as the common literature indicates that US financial channel can be a global source of risk (Longstaff et al. (2011), Augustin and Tedongap (2014)). Consider also that contagion from US bond market has significant implications in terms of expected tightening of the Fed's monetary policy and as such it has been recently attributed to the surge in the CDS spreads occurred from end-2016 (DeGrauwe et al. (2017)).

Our empirical analysis provides three main findings. First, over the period from 2008 to 2013, we detect three main sovereign risk zones. The safe zone is characterized by a low unemployment rate and moderate Debt/GDP ratio, the risky zone has a high unemployment rate or high Debt/GDP ratio, and the high risky zone is characterized by a high unemployment rate, high Debt/GDP ratio, and significant sovereign dependency. For each selected leading indicator we provide a corresponding risk threshold, also allowing non-linear interactions among them with potentially relevant policy implications. Indeed, an unemployment rate up to 11.75 percent together with a Debt/GDP ratio up to 119.6 percent should maintain sovereign spreads within a safe zone. Moreover, when unemployment rate exceeds 11.75 percent or Debt/GDP ratio is crossing 119.6 percent, the sovereign risk can move towards risky or very high risky zone, based on interactions with the inflation rate and copula-based contagion measures. In terms of statistical accuracy our model turns out to be robust in-sample and out-of-sample, outperforming competing panel models (pooled OLS, country fixed effects, country and time fixed effects).

Second, on average we estimate an impact on the CDS spreads approximately of $-105 \mathrm{bps}$ in the period 2013-2017 due to contagion mitigation. In other words, if the sovereign risk sensitivity exhibited in the years 2013-2017 was the same as the one observed during the period 2008-2013, we would have had higher spreads for all countries (excluding Greece): 76bps for France and Germany versus actual 26bps and 11bps, respectively; 117bps versus 48bps for Ireland; 259bps versus 105bps for Italy; 266bps versus 187bps for Portugal; 284bps versus 72bps for Spain.

Third, the role played by key macroeconomic fundamentals remained the same over the entire period 2008-2017. A comparative analysis between the crisis period 2008-2013 and the postQuantitative Easing years 2013-2017 shows a primary role for Debt/GDP ratio and the unemploy-

1 Caporin et al. 2018) study the same group of countries adding also a non-EMU country, UK. We stay focused to countries which are EMU members in order to "contain" the currency risk. 
ment rate in both sub-periods, which also maintained fairly the same risk thresholds. Instead, CDS contagion dropped significantly from 2008-2013 to 2013-2017, thus lowering the corresponding risk thresholds. We ascribe to this factor the general downturn of the CDS spreads occurred in the Eurozone, excluding Greece, over the years 2013-2017. In other words, the excessive sovereign risk pricing we observed during the crisis was massively due to contagion, as the risk sensitivity towards macro fundamentals remained unchanged through the sub-periods.

The articulation of the paper is as follows: Section 2 describes the data. Section 3 provides detailed information on our statistical procedures. In Section 4 we present the results for crisis and post-crisis periods, and Section 5 concludes.

\section{Data}

To measure the sovereign risk for GIIPS, France, and Germany, we use the sovereign CDS insurancelike contracts used to protect investors against losses on sovereign debt. CDS are over-the-counter (OTC) products quoted in basis points per year, the so called CDS spread 1 . This is the cost that must be paid by the buyer of CDS to the seller for the contingent claim in the case of a credit event, for the sovereign CDS represented by nonpayment or forced restructuring of sovereign debt. Therefore, sovereign CDS provide a market-based real time proxy for sovereign credit quality and default risk. Buyers of the sovereign CDS may or may not own the underlying government bonds. The latter case is termed naked sovereign $\mathrm{CDS}_{2}^{2}$, which is ascribed to market speculation ${ }^{3}$, As pointed out by Longstaff et al. (2011), these contracts are typically more liquid than the corresponding sovereign bonds and thus they offer better measures for the sovereign risk 4 . Analytically, we collected daily quotes over the period from $01 / 02 / 2008$ to $05 / 23 / 2017$ splitting the sample in (a) the crisis period from 01/02/2008 to 09/30/2013; (b) the post-Quantitative Easing period from $10 / 01 / 2013$ to $05 / 23 / 20175$. As discussed in the introduction, since the US financial channel is an important global source of risk, we also collected 5-yr US sovereign CDS data.

In our model specification, we use both macroeconomic and financial variables according to the recent findings from the large literature on the determinants of the sovereign CDS (see Augustin et al. (2014) for an exhaustive literature review of the key papers on the subject and more recently Doshi et al. (2017)). Specifically, the country-specific macroeconomic factors are the following: Debt/GDP ratio, exports/GDP ratio, GDP growth rate, industrial production, inflation and the unemployment rate. To avoid possible reverse causality between sovereign CDS and macroeconomic factors, we lagged all the macro-variables by one period. Moreover, since their frequency is different from that of the CDS data, the missing values of the predictors are filled with the latest available observation until their new release. This procedure is in line with Beber et al. (2014) who extracts from the cross-section of macroeconomic news release a set of factors (principal components) by solving the missing data problem by filling the last observed release until the next announcement.

Since the pervasiveness of the feedback loop between the debt crisis and the financial sector is one key feature of the sovereign debt crisis, we also include financial variables in our sovereign risk

\footnotetext{
${ }^{1}$ A short description of the CDS and the euro area CDS market as of 2012 can be found at ECB $(2012)$

${ }^{2}$ German Federal Financial Supervisory Authority prohibited naked buying of CDS based on euro-denominated government bonds on May 19, 2010, and little after the European Parliament passed the ban on same naked CDS on December 1, 2011. The regulation was in effect on November 1, 2012.

${ }^{3}$ See Oehmke and Zawadowski (2017) for a comprehensive investigation on the motivations for trading in CDS markets and, more broadly, on the economic function played by these markets.

${ }^{4} 5$-yr sovereign CDS are the most liquid contracts traded in the market, while others maturities, like 6 months, 1- 2- 3- 4- 57- 10- 15- 20- 30- years, are also available.

${ }^{5}$ For the Greek CDS spread only 1414 quotes out of 1505 are available over the crisis period. In fact, since the end of 2009 and the start of 2010, the Greek CDS spread traded at extraordinary levels. On April 22, 2010, the Greek CDS spread reached the 700bps and afterwards the Greek CDS contracts have been converted to up front, as the protection seller had to pay up front a premium to the protection buyer, as the elevated Greek CDS basis mapped the sentiment of the market participants that the situation would be unsustainable in the long term. In the meantime, the volume of dealers quoting Greek CDS was not sufficient for the key providers of derivative pricing information to determine an official live price.
} 
modeling. We use the following indices: the US Banks 5-yr CDS index, the Euro Other Financials 5-yr CDS index and US Other Financials 5-yr CDS index.

The sovereign CDS data comes from Markit, the CDS indices from Thomson Reuters Datastream and the macroeconomic data from Eurostat. A full description of the dataset is in the Online Appendix.

\section{Methodology}

\subsection{Computing Dependency in the Sovereign Risk Dynamics: A Flexible Copula Model}

During the inspected period the Euro CDS spreads have shown both regime-switching and nonlinear dependencies, so we have adopted a more general dependency measure than the linear correlation. This is based on Arakelian and Dellaportas (2012) who provided a flexible threshold model that estimates copulas which vary across time and capture a rich dependency structure between bivariate time series. Their work is based on the assumption that in different time periods, separated by thresholds, different volatilities and copula formulations can adequately explain the dependency between two financial assets which comove non-linearly and possibly showing changes in regime. By assuming that the number and location of thresholds are unknown and need to be estimated, the methodology considers models with different volatilities, copula functions, number of thresholds and threshold locations. A reversible-jump MCMC algorithm is run thus obtaining samples from the posterior density of these models, and a Bayesian model-averaging estimation approach constructs a posterior density of Kendall's $\tau$ (Kendall (1938), Nelsen (1999)), marginalised over all models and parameters within each model. In doing this, Arakelian and Dellaportas (2012) propose to use the posterior mean of this density as a measure of the dependency of two asset: 1 . When implementing the Arakelian and Dellaportas (2012) procedure, and specifically when applying the reversible-jump MCMC algorithm to some CDS pairs, we notice that the mixing of the Markov chain over the product space of models and parameters was not satisfactory. We, therefore, adopt the population-based simulation suggested by Jasra et al. (2007). This method generates $L$ parallel-sampled auxiliary Markov chains with target densities $\pi_{l} \propto \pi^{\zeta_{l}}$, where $\pi$ denotes the posterior density from which we need to obtain samples and $\zeta_{l}$ are ordered parameters $0<\zeta_{l}<\zeta_{l-1}<\ldots<\zeta_{1}<1$. The densities $\pi_{l}$ serve as independent Metropolis-Hasting proposal densities for the main chain with target density $\pi$. At each iteration, one auxiliary density $\pi_{l}$ is chosen at random and used together with the current sampled point of $\pi_{l}$ at the usual acceptance ratio of the main chain. In the terminology of Jasra et al. (2007), this is an exchange move in the population reversible-jump algorithm. We use the strategy proposed by Jasra et al. (2007), whereby five auxiliary chains are chosen with values of $\zeta_{l}$ being updated as a linear function of their past value and the acceptance rate of the process calculated within the burn-in period ${ }^{2}$.

\subsection{Sovereign Risk Stratification and Variable Importance}

3.2.1. Regression Trees. Having the objective to identify the key predictors for stratifying the sovereign risk in specific "risk zones", the core question of our study is how to combine non-linear time-varying CDS dependencies (our proxy for contagion) with country-specific macroeconomic fundamentals. Methodologically, we require a procedure to elucidate how Kendall's $\tau$ and macroeconomic fundamentals interact non-linearly then affecting the CDS spreads. What we are aiming

\footnotetext{
${ }^{1}$ Their empirical study explains interesting contagion effects in the Asian and Mexican crises.

${ }^{2}$ We develop a MATLAB code to implement the method. Description of the MATLAB codes used are in the Online Appendix https://www.researchgate.net/publication/322925040_Online_Supplementary_Material_for_Sovereign_Risk_ Zones_in_Europe_During_and_After_the_Debt_Crisis
} 
for is detecting the most important leading indicators and modeling their key interactions through specific risk thresholds to map the paths along which countries can move towards dangerous risk zones. To do this we employ regression trees approach.

Regression trees are nonparametric models constructed by recursively partitioning a data set through its predictor variables with the objective of optimally predicting a response variable which can be continuous or categorical. The beauty of the procedure, which is definitely what we need for our main objective, is in uncovering forms of nonlinearity and identify multiple data regimes from a set of predictor variables. The approach has been applied in different studies and turned out to be extremely robust and efficient exploring banking and sovereign crises (for example, see Manasse and Roubini (2009), Savona and Vezzoli (2015)) and proves to be extremely robust and efficient in exploring complex and nonlinear relationships also offering an early warning system by construction, as the final model is in the form of a series of splitting rules leading to final nodes (what we called, "risk zones"). Moreover, regression trees are conceived with the aim of improving outof-sample predictability. To achieve this, they are estimated through a cross-validation estimation procedure whereby the sample is partitioned into subsets, so that the analysis is initially performed on a single subset (the training sets), whereas the other subsets are retained for subsequent use in confirming and validating the initial analysis (the validation or testing sets). Mathematically, having data consisting of $R$ inputs and a continuous response, $Y$, for each of $N$ observations, the algorithm needs to decide on the splitting variables, the split points, and the topology (shape) of the tree. To do this, the algorithm partitions the input space $\mathcal{S}$, namely the set of all possible values of $\mathbf{X}(\mathbf{X} \in \mathcal{S})$, into disjoint regions $T_{k}$ with $k=1,2, \cdots, K$, so that $\mathcal{S} \subseteq \bigcup_{k=1}^{K} T_{k}$. The underlying response-predictor structure $f(\mathbf{X})$ is represented by the piecewise constant functions $g_{k}$ fitted over the input subspace:

$$
f(\mathbf{X})=\sum_{k=1}^{K} g_{k} I\left(\mathbf{X} \in T_{k}\right) .
$$

where $g_{k}$ is the parameter that associates the $k$ th value with the corresponding node and $I$ denotes the indicator function taking the value of 1 if $\mathbf{X} \in T_{k}$. As a result, predictions are computed by the average of the $Y$ values within the terminal nodes, i.e.

$$
\widehat{Y}_{i}=\widehat{g}_{k}=\frac{\Sigma_{\mathbf{X} \in T_{k}} Y_{i}}{N_{k}}
$$

The sum of squares $\sum(Y-f(\mathbf{X}))^{2}$ is used as the criterion of minimization, thus obtaining a mapping of the response variable which is optimal for the number of final clusters, the best predictors and corresponding thresholds, and the predictions for the $Y$ variable 1 .

3.2.2. Random Forest. To assess the importance of the leading indicators used to explain the dynamics of the sovereign CDS we also adopt the random forest procedure. This ensemble learning inference procedure is essentially a collection of regression trees using different combinations of variables and samples (Breiman (2001a); Breiman (2003)). More formally, having a panel data of $N$ observations over a time length $T$ and considering $R$ candidate predictors, the algorithm runs as follows:

\footnotetext{
${ }^{1}$ For each predictor, the procedure starts by considering all the possible binary splits obtained from the starting node (the first node is the sample as a whole) considering each realization as possible splitting value (from min to max) and calculating the corresponding reduction in the MSE (node impurity) generated by the split from the starting node to the sub-nodes; the best split is the value for the predictor which attains the maximum reduction in node impurity. The procedure is run for each predictor at each split and the selected variables with corresponding threshold are those that most reduce the loss function in each partition. See Hastie et al. (2009) for more technical details.
} 
(i) Bootstrap $n<N$ sub-samples with replacement from the original data of $N$ observations.

(ii) Run a regression tree on the bootstrap samples by randomly selecting $q<R$ predictors from the total $R$ predictors.

(iii) Repeat the previous steps obtaining thousands of regression trees (in our case $3,000^{1}$ ). Hence, at each run, the trees are calculated by randomizing over two dimensions, the subsample of data and a (small) subset of all the variables.

(iv) Estimate the mean squared error (MSE) from the bootstrap samples, the so-called out-ofbag $(\mathrm{OOB}): M S E_{O O B}=\frac{\sum_{i=1}^{n}\left(Y_{i}-\widehat{Y}_{i O O B}\right)^{2}}{n}$, where $\widehat{Y}_{i O O B}$ denotes the average prediction for the $i$ th observation from all trees for which this observation has been OOB.

(v) To assess the importance attributed at each variable based on the MSE reduction (Breiman (2003)), MSE is computed for the generic regression tree over all the OOB observations as:

$$
M S E_{O O B, \text { tree }}=\frac{\sum_{i_{\in O O B_{\text {tree }}}=1}^{n}\left(Y_{i}-\widehat{Y}_{i}^{\text {tree }}\right)^{2}}{n_{O O B}^{\text {tree }}},
$$

where $\widehat{Y}_{i}^{\text {tree }}$ are the predictions of the regression tree, $i$ are its observations over OOB data only, and $n_{O O B}^{\text {tree }}$ is the number of OOB observations in the same regression tree.

(vi) Compute the MSE reduction associated to each $X_{r}$ covariate in $\mathbf{X}$ by comparing the MSE with and without $X_{r}$ permuted thereby obtaining the following Variable Importance $(V I)$ measure,

$$
V I_{r}=M S E_{O O B}^{\text {tree }}-M S E_{O O B}^{\text {tree }}\left(X_{r, p e r m u t e d}\right) .
$$

The idea behind this measure is that, if a regressor $X_{j}$ does not have a significant contribution in predicting $Y$, it makes no difference if the values for the predictor are randomly permuted in the OOB data before the predictions are generated.

We rank all predictions according to the $V I_{r}$ measure distinguishing the more influential variable (with the highest MSE reduction value) from the lowest variables (with the lowest MSE reduction values).

(vii) Compute the relative measure, VIM, by normalizing the $V I$ of each variable over the highest value obtaining the normalized variable importance measure, $V I M_{r}$ which varies from 1 to 100 :

$$
V I M_{r}=\frac{V I_{r}}{V I_{r}^{\text {highest }}} \times 100
$$

\section{Results}

\subsection{Crisis Period 2008-2013}

4.1.1. Sovereign Risk and Copula-Based Dependencies. Preliminary, we apply our threshold copula model to compute pairwise correlations in the form of Kendall's $\tau$ dependencies to daily differences in Euro sovereign CDS and CDS indices, next inspect how the level of each sovereign CDS is affected by each pair of Kendall's $\tau$ dynamics, in order to understand which of the pairwise dependencies exert the higher impact on sovereign risk dynamics (detailed results are in the subsections 4.1 and 4.2 in the Online Appendix). As a whole, the results are in line with the findings of Gonzlez-Hermosillo and Johnson (2014), in that Spain and Italy show considerable co-dependence in explaining each others volatility, while Greece assumes a scant role as primary

\footnotetext{
${ }^{1}$ It was heuristically shown that the accuracy of random forest converges around 3,000 trees.
} 
contagion channel. Our results indeed indicate that on average, the contribution of Greece only appears when considering co-evolution with Germany, although its importance is modest when compared with other dependencies (see Fig.5 in the Online Appendix). As discussed by GonzlezHermosillo and Johnson (2014), the mechanisms underlying the contagion propagation can follow very complex channels that are not related only to pure sovereign risk interconnections. Contagion can arise because of adverse market price dynamics, worsening liquidity problems, connections with the financial sector (banks and other financial intermediaries) and monetary policy tightening. The challenging issue is how to separate all these factors and then understand all possible risk patterns and corresponding triggers. This is exactly the theme of the next section, which is devoted to detecting sovereign risk zones, shedding light on their deep-rooted causes, dynamics and risk signals.

4.1.2. Risk Mapping. We now provide a complete and pragmatic risk mapping for the sovereign risk in the Eurozone also exploring the importance of each leading indicator assumed over time. As discussed, to do this we use regression trees to stratify the sovereign risk, together with a random forest to assign the variable importance. Computationally, we start by looking over all the data simultaneously in a panel-data regression trees approach. Our response variable is all the times series of the seven Eurozone sovereign CDS stacked together, while the set of possible leading indicators (the covariates) contains fourteen variables distinguishing between contagion-based and fundamental-based measures. The contagion-based measures, namely nonparametric daily pairwise dependencies computed through Kendall's $\tau$ for each of the seven Eurozone sovereign CDS, are the following:

(i) the Kendall's $\tau$ between France and Germany $\left(\tau_{F r, G e r}\right)$ representing the strength and the direction of association that exists between core countries;

(ii) the Kendall's $\tau$ between all the pairs of GIIPS $\left(\tau_{G I I P S}\right)$, capturing the strength and direction of association between the peripheral countries;

(iii) the Kendall's $\tau$ between a single and the rest of the group of European countries ( $\left.\tau_{\text {EuroSvgn,EuroSvgn }}\right)$ representing a synthesis of the European dependencies from the perspective of a single country;

(iv) the Kendall's $\tau$ between a single sovereign CDS spread and the Euro Banks 5-yr CDS index $\left(\tau_{\text {svgn,EUBanks }}\right)$ assessing the sovereign and European banking system loop dynamics;

(v) the Kendall's $\tau$ between a single sovereign CDS spread and the Euro Other Financials 5-yr $C D S$ index $\left(\tau_{\text {svgn,EUOther }}\right)$;

(vi) the Kendall's $\tau$ between a single sovereign CDS spread and the sovereign US 5-yr CDS spread $\left(\tau_{\text {svgn,US }}\right)$ assessing the connections with the US sovereign risk dynamics;

(vii) the Kendall's $\tau$ between a single sovereign CDS spread and the US Banks 5-yr CDS index ( $\tau_{\text {svgn,USBanks }}$ ) assessing the sovereign-US banking system loop dynamics;

(viii) the Kendall's $\tau$ between a single sovereign CDS spread and the US Other Financials 5-yr $C D S$ index $\left(\tau_{\text {svgn,USOther }}\right)$.

While the country-specific fundamentals are:

(ix) the $D e b t / G D P$ ratio;

(x) the exports/GDP ratio;

(xi) the GDP growth;

(xii) the industrial production;

(xiii) the inflation rate and

(xiv) the unemployment rate.

The final regression tree (assembled as described in the methodological section) allows a clear understanding of the different risk regimes which are endogenously detected by the same algorithm. Note that no a priori knowledge about the timing of the shifts is assumed. The concept of regime 
(and the change in regime) is used here as a proxy for spatio-temporal risk stratification, leading to a number of final risk zones that include important insights in terms of their time-varying composition and the values assumed by the selected leading variables.

4.1.3. Inside the Risk Zones. The risk stratification we obtain through regression trees analysis is reported in Fig,2. The model selected four contagion-based variables and four countryspecific fundamentals out of the fourteen candidate covariates. The eight selected variables are the following: the Kendall's $\tau$ between the single sovereign CDS spread and GIIPS's CDS spreads, $\tau_{\text {svgn,GIIPS }}$; the Kendall's $\tau$ between the single sovereign CDS spread and the rest of the Euro sovereign CDS spreads, $\tau_{\text {svgn,EuroSvgn }}$; the Kendall's $\tau$ between the single sovereign CDS spread and the Euro Other Financials 5-yr CDS index, $\tau_{\text {svgn,EUOthFin; }}$; the Kendall's $\tau$ between the single sovereign CDS spread and the sovereign US 5-yr CDS spreads, $\tau_{s v g n, U S}$; the Debt/GDP ratio; the $G D P$ growth; the inflation rate; the unemployment rate. The regression tree shows seventeen final nodes, although the corresponding mean values of the expected CDS spreads allow us to make some grouping based on specific risk levels, from low to very high, as explained below. We inspect each of the seventeen risk regimes from different perspectives, such as the expected CDS spread, the threshold values computed by the algorithms and the time-varying country composition of each node, looking primarily at the values assumed both by leading covariates and those that are potentially informative, to come up with a complete mapping of each risk zone. With the objective of inspecting the anatomy of each final node, we also follow a visual mining philosophy thereby reducing data interpretation complexity through visualization. Specifically, to give an overview of the distributions taken on by all variables within each final node, and not only of those selected by the regression tree, we relied on the heatmaps, commonly used to emphasize data above or below specific thresholds as "hot" or "cold" colors, respectively. In our analysis, low values (cold colors) are in blue, high values (hot colors) are in red, while values around the mean (warm colors) are in yellow 1 . By starting from the top node $\left(\tau_{\text {GIIPS }}\right)$ and using the corresponding splitting rules $(\geq$ or $<$ ), we move along the path traced by the values of the selected variables: if the value in each node agrees with the splitting rule the move is to the left, otherwise, it is to the right. This process leads to the final nodes, where the expected value of the dependent variable is given.

As a whole, a first interesting result obtained is the discrimination between two main macroregions through the $\tau_{\text {GIIPS }}$ indicator (the Kendall's $\tau$ with GIIPS's CDS), which is placed at the top of the tree with a threshold value of 0.3167 . These two macro-regions are:

(i) the Greek Only Area, corresponding to values of the $\tau_{\text {GIIPS }}$ less than 0.3167, leading on the right of the tree towards extremely high risk levels, where the values of expected CDS in each final node range from $1,515 \mathrm{bps}$ to $24,706 \mathrm{bps}$;

(ii) the Euro Sovereign Risk Area corresponding to values of the $\tau_{G I I P S}$ indicator greater than 0.3167 , leading to different risk zones spanning from low (76bps) to high risk levels $(1,217 \mathrm{bps})$.

\subsubsection{The Greek Only Area.}

(i) High sovereign dependency with moderate financial contagion. The zone is associated with Kendall's $\tau$ with all Euro sovereign CDS ( $\tau_{\text {EuroSvgn,EuroSvgn }}$ ) greater than 0.5209 together with Kendall's $\tau$ of sovereign CDS with the Euro Other Financials 5-yr CDS in-

\footnotetext{
${ }^{1}$ Predictor values are standardized to avoid different scale orders, and depicted by a rectangular tiling of different colors within the data matrix. Heatmaps also compute two hierarchical cluster analyses: one is being implemented on the contagionbased variables and country-specific fundamentals and the other one on the observations (more precisely, on the countries in correspondence to different years), thereby realizing two dendrograms appended on the $\mathrm{x}$ - and $\mathrm{y}$-axes, respectively (Ling (1973)). In doing this, the columns and the rows of the data matrix are permuted based on column and row means. In this way, similar values are placed near each other according to the clustering algorithm used in the analysis (Sneath (1957)).
} 
$\operatorname{dex}\left(\tau_{\text {svgn,EUOthFin }}\right)$ less than 0.4606 , and inflation rate less than $1.9 \%$. Following this risk path, the expected CDS spread is dramatically high and equal to 24,706bps. The expected sovereign risk tends to be less pervasive when inflation is greater than the selected threshold, and it currently reaches the level of 7,726bps. Looking at the corresponding heatmaps (Fig.6 in the Online Appendix), we note that for both final nodes the Kendall's $\tau$ with US Banks 5-yr CDS index is high for both final nodes, together with high values for the unemployment rate and Debt/GDP ratio.

(ii) High sovereign dependency with high financial contagion. Unlike the previous risk zone, here high Kendall's $\tau$ with the Euro sovereign CDS ( $\tau_{\text {EuroSvgn, EuroSvgn }}$ ) moves in tandem with high Kendall's $\tau$ of sovereign CDS with the Euro Other Financials 5-yr CDS index $\left(\tau_{\text {svgn,EUOthFin }}\right)$; moreover, GDP growth with inflation lead to different sovereign risk values: when GDP growth is higher than $6.85 \%$, the expected CDS is $14,888 \mathrm{bps}$; instead when the GDP growth is below $6.85 \%$, an upward moving inflation (more than $2.95 \%$ ) leads to 2,156bps against 9,328bps, which is the expected CDS value when inflation is low (and less than 2.95\%). Heatmaps for the three final nodes (see Fig.6 in the Online Appendix) confirm the high financial contagion by showing high values for dependencies with US and Euro Other Financials 5-yr CDS index as well as US Banks 5-yr CDS index.

(iii) Contained sovereign dependency. In this risk zone, the Kendall's $\tau$ of the Euro sovereign CDS spread is less than 0.5209. The final nodes ultimately depend on inflation, for which deflation states seem to contain CDS turbulence, as the expected CDS spread is 1,515bps when inflation is less than $-0.25 \%$, whereas having inflation greater than the threshold leads to a slightly higher level of sovereign risk 1 . The corresponding heatmap highlights high values for the unemployment rate and Debt/GDP ratio.

4.1.5. The Euro Sovereign Risk Area. This macro area includes many risk regimes that together well stratify the Euro sovereign risk area for all the seven countries over the entire period, but clearly with the exception of Greece during the period from June 2011 to October 2013. As discussed above, this macro area is identified by values of the median Kendall's $\tau$ with GIIPS greater than 0.3167 . Next, based on other leading indicators selected by the regression tree, the next splits lead to ten final nodes we group into three main risk zones.

(i) Safe Zone. This regime exhibits low unemployment rate (less than 11.75\%) and moderate public indebtedness relative to GDP (Debt/GDP ratio $<119.6 \%$ ), and expected CDS spread is 76bps. This is the lower value among all the final nodes and some very interesting insights can be gained by inspecting the time-varying country composition, which completely

\footnotetext{
${ }^{1}$ While deflation complicates debt sustainability and is related to large contractions, which in turns are both related to sovereign risk, it is more appropriate to examine the shocks driving down inflation, as the risk of deflation assessment demands the identification of the nature and the persistence of the determining factors and, in particular, the degree to which inflation developments can be attributed to supply-side or demand-side forces. As discussed in ECB (2014), the overall price index may turn negative for a short period on the back of transitory supply-side shocks, such as commodity price movements, as it occurred in the euro area and in other countries in 2009. However, a period of negative annual inflation does not in itself imply deflation, in a meaningful economic sense, unless the price declines become generalised and entrenched in inflation expectations. For instance, if longer-term inflation expectations remain stable, the ebbs and flows in commodity prices are bound to exert only transitory effects on inflation. Furthermore, it is crucial to disentangle the impact of supply-side shocks resulting from structural reforms, which may have implications for inflation developments over the policy-relevant horizon. While structural reforms may initially lead to downward pressures on inflation rates, reflecting also supply-side improvements in the economy, inflation can be expected to pick up over time as aggregate demand gradually recovers. In the case of the euro area, one should not confuse relative price adjustments with overall changes in the price level: to speak meaningfully of deflation, the generalised and prolonged fall in the price level should be broadly based across countries. There is no risk of outright deflation as long as euro area HICP (Harmonised Index of Consumer Prices) inflation is in line with price stability. Negative inflation rates in individual countries may, on occasion, be consistent with the normal functioning of a monetary union, as they help to restore competitiveness, i.e. they may be symptomatic of supply-side induced relative price adjustments. Under these circumstances, a period of deflationary pressure may have been seen beneficial for Greek growth, thereby alleviating the sovereign risk, as it seems to prove the splitting rule on inflation of our regression tree.
} 
changed as the crisis began to unfold. Fig.7 and Fig.8 in the Online Appendix report the country composition and the heatmap. The country composition is identified by observing the CDS values with corresponding country names for each node on a monthly basis. For this safe zone regime, we observe that all seven countries are included in this cluster from January 2008, and only starting from September 2008, when the Lehman Brothers collapsed, did non-safe countries begin to leave this regim ${ }^{2}$. Therefore, markets became highly sensitive to Debt/GDP ratio together with the unemployment rate, and more specifically an unemployment rate greater than $11.75 \%$ or a Debt/GDP ratio greater than $119.6 \%$ signals an expected move towards risky or high-risk zones.

(ii) Risky Zone. This risk regime is characterised by low unemployment rate with high Debt/GDP ratio or with the high unemployment rate and includes the following sub-zones: the low unemployment rate with high Debt/GDP ratio scenario and the high unemployment rate scenario. In the first scenario, inflation enters the risk stratification process by splitting between low (less than 3.15\%) and moderate (greater than 3.15\%) inflation, leading to an expected CDS spread of 219bps and 445bps respectively. The time-varying country compositions of the two final nodes and the heatmaps (Fig.10 and Fig.11 in the Online Appendix, respectively) highlight some further interesting differences. The first node, showing an expected CDS value of 219bps, includes Greece from March 2009 to March 2010, and Italy from September 2010 to September 2011 (excluding January and February 2011) and October 2012 to January 2013. The corresponding heatmap shows low values for exports/GDP ratio with high values for contagion-based measures, specifically the Kendall's $\tau$ with France and Germany and with GIIPS. The second node, showing an expected CDS value of 445bps, again includes Greece, from April to May 2010, and Italy, from September 2011 to October 2012. Looking at the corresponding heatmaps, we note high values for the Kendall's $\tau$ with France and Germany on the one hand, and on the other, low values for Kendall's $\tau$ with of the Euro sovereign CDS with US Other Financials 5-yr CDS index ( $\left.\tau_{\text {EuroSvgn,USOthFin }}\right)$. In other words, it seems that the form of contagion that really matters concerns dependency with the core countries of the Eurozone - France and Germany - together with high Debt/GDP ratio and moderate inflation. If we consider these findings together, it is of particular interest that the first effects on the re-pricing of sovereign risk in Greece, occurring at the end of 2009 and continuing with the spike of the CDS from April to May 2010 when Greece applied for financial support, were the same in terms of their underlying contagion-based and fundamental-based triggers as those for Italy from September 2010 to January 2013. The second scenario includes three final nodes which modulate between low (less than 66.45\%) and moderate-to-high (between $66.45 \%$ and 93.65\%) Debt/GDP ratio, and also point to high Debt/GDP ratio with low dependency with other Eurozone sovereign risks dynamics. In the first sub-scenario, the corresponding heatmaps display for both nodes (with expected CDS spread 160bps and 370bps, respectively) high values for Euro sovereign contagion (Kendall's $\tau$ with GIIPS and France and Germany) and Euro banking contagion (Kendall's $\tau$ of sovereign CDS with the Euro Banks 5-yr CDS index, $\left.\tau_{\text {svgn,EUBanks }}\right)$. By observing the country composition over time, we note that Spain and Ireland were in both nodes, while Portugal was in the final node only, with moderate-tohigh Debt/GDP ratio. In the second sub-scenario, corresponding to the final node with 285bps as expected sovereign risk level, the heatmap displays low values for US financial contagion (captured by Kendall's $\tau$ ) and industrial production, thereby mixing contagionbased and fundamental-based indicators. This was the case for Portugal and Italy over the

\footnotetext{
${ }^{2}$ The first country moved to other regimes was Spain in September 2008, followed by Greece in April 2009, Ireland in May 2009, Portugal in May 2010, and Italy in September 2010. Starting from 2011, only France and Germany remained in the safe zone until the end of the crisis period. These findings confirm the "wake-up call" phenomenon in the Eurozone (Goldstein (1998)), since markets ignored deteriorating fundamentals during times of non-crisis and became highly sensitive upon the onset of crisis.
} 
November 2012-September 2013 period (see Fig.11, Online Appendix) where high values for Debt/GDP ratio and the unemployment rate moved along with low contagion. This explains why the sovereign risk was slightly lower than it was for Ireland, Spain, and Portugal, clustered inside the node of 370bps as expected CDS spread: in such a case, public indebtedness was associated with significant sovereign and banking contagion.

(iii) High Risk Zone. The main features of this very dangerous zone, which leads towards very high sovereign risk levels, are high unemployment rate (greater than $11.75 \%$ ), associated with high Debt/GDP ratio (greater than 93.65\%) and significant sovereign contagion (Kendall's $\tau$ of Euro sovereign CDS greater than 0.4872). Taken together, these indicators (with corresponding red flags) signal extreme risk sensitivity, which is reflected into expected CDS spreads spanning from 575bps to $1,217 \mathrm{bps}$ covering four final nodes. We identified the following two sub-zones based on such a final risk partition:

a) The GIIPS contagion scenario: In this scenario, the median Kendall's $\tau$ among GIIPS is greater than 0.4924 and leads towards two final nodes. The first denotes high dependency with Euro Other Financials 5-yr CDS index and low GDP growth; see Fig.12 of the Online Appendix. Discontinuously, Greece (May-June 2010), Portugal (January-May 2011 ${ }^{1}$ and September-October 2012), Spain (November 2011-October 2012) populated this node which exhibits 575bps as expected risk level. The second node which indicates higher risk level of $842 \mathrm{bps}$ is similar to the previous one but differs because of its low dependency with Euro Other Financials 5-yr CDS index (see Fig.12, Online Appendix). This was the case for Greece (from July 2010 to March 2011), Ireland (from April 2011 $1^{2}$ to October 2011), and Portugal (from May to June 2011), as depicted in Fig.11 of the Online Appendix showing the country composition over time.

b) The low US-based sovereign dependency: Here, the two final nodes show significant risk level shift, since the first exhibits $717 \mathrm{bps}$ and the second 1,217bps. While both nodes are characterised by extremely low (first node) or low (second node) Kendall's $\tau$ towards the sovereign US 5-yr CDS spread dynamics, looking at the corresponding heatmaps (Fig.12, Online Appendix,), we observe that what probably reflects higher risk is the Kendall's $\tau$ of sovereign CDS with the US Other Financial 5-yr CDS in$\operatorname{dex}\left(\tau_{\text {svgn,USOthFin }}\right)$. Indeed, the second node includes high values for Kendall's $\tau$ of sovereign CDS with the with US Other Financials 5-yr CDS index, in particular for some parts of the final partition (as it is discussed below corresponding to Greece), while the first node shows low values for this indicator. In fact, this different dependency towards US Other Financials 5-yr CDS index dynamics arises when observing the country composition of the two final nodes with corresponding time series of such a variable. Portugal and Ireland are placed within the node with expected CDS spread at 717bps, from June to October 2012. During this period both countries exhibited extremely low values of Kendall's $\tau$ of sovereign CDS with the US Other Financials 5-yr CDS index ( $\left.\tau_{\text {svgn,USOthFin }}\right)$ around 0.03. On the other hand, Greece and Portugal are within the node with 1,217bps as expected CDS spread for the period from March 2011 to June 2012 (Greece: March-June 2011; Portugal: July 2011-June 2012). During this period, the values of Kendall's $\tau$ of sovereign CDS with the US Other Financials 5-yr CDS index ( $\left.\tau_{\text {svgn,USOthFin }}\right)$ were on average around 0.16 with a big difference between Greece, that show an average value of 0.46 , and Portugal, that show an average of 0.09 .

\footnotetext{
${ }^{1}$ Portugal applied for financial support in April 2011.

${ }^{2}$ Ireland is already in financial support program since November 2010.
} 
4.1.6. In-Sample Robustness Check. To assess the robustness of our risk zoning, we check the statistical reliability of the results by comparing the performance of our model with those from the natural model competitors, namely the panel model specifications: (i) OLS (Ordinary Least Squares) pooled model; (ii) panel model with country fixed effects; (iii) panel model with country and time fixed effects.

Analytically, we used the same set of variables when running the regression tree to estimate the following model:

$$
Y_{j, t}=\beta_{j}^{\top} x_{j, t}+\lambda_{j}+\gamma_{t}+\epsilon_{j, t}
$$

where $Y_{j, t}$ is the daily CDS spread of country $j$ at time $t, \beta_{j}^{\top}$ is the transposed vector of coefficients to be estimated, $x_{j, t}$ is the vector of covariate values of country $j$ at time $t, \lambda_{j}$ is the country fixed effect and $\gamma_{t}$ is the time fixed effect; $\epsilon_{j, t}$ is the error term at time $t$ for country $j$. Note that, when estimating OLS pooled model $\lambda_{j}$ and $\gamma_{t}$ are not included; when estimating the panel model with country fixed effect $\lambda_{j}$ is included, and finally when estimating the panel model with country and time fixed effects both $\lambda_{j}$ and $\gamma_{t}$ are included. Table 1 reports estimation results of the three-panel model specifications. As a whole, all the models show adequate statistical significance for the selected covariates, excluding industrial production and the Kendall's $\tau$ between a single sovereign CDS and the US Banks 5-yr CDS index, for OLS pooled model; exports/GDP, inflation and the Kendall's $\tau$ between France and Germany, for panel model with country fixed effects. The explanatory power of the three models shows a slight outperformance of the OLS pooled model $\left(\bar{R}^{2}=0.6252\right)$ compared with panel model with country $\left(\bar{R}^{2}=0.5635\right)$ and country-time $\left(\bar{R}^{2}=0.5486\right)$ fixed effects, respectively.

To compare the statistical reliability of these competitors against our regression tree, we computed the explained variation $\left(R^{2}\right)$, Mean Squared Errors (MSE) and Root Mean Squared Errors (RMS). Table 2 summarizes the results, showing a significant overperformance of regression trees approach with an explained variation around 0.94; moreover, the MSE and RMSE of the competing models are two (RMSE) and four-to-eight (MSE) times greater than the corresponding statistics of the regression trees approach. We then prove the strong statistical reliability of our risk zoning also compared with alternative model specifications.

4.1.7. Risk Indicators and their Importance. After inspecting the statistical reliability of the model, we now conclude our risk stratification analysis by exploring the role played by all risk indicators in terms of their impact on sovereign risk dynamics and examine how contagion-based and country-specific indicators exerted different impacts over time. To do this, we first run the random forest algorithm on a monthly basis and compute the VIM (eq.3) for each variable (Detailed results are in Subsection 4.2 in the Online Appendix), secondly, to examine the importance assumed by the variables clustered according to contagion and macro fundamental variables, we extract the first principal component from the VIM of the first subgroup (pc-contagion) of the eight contagion-based variables, $\tau_{F r, G e r}, \tau_{G I I P S}, \tau_{\text {EuroSvgn,EuroSvgn }}, \tau_{\text {svgn,EUBanks }}, \tau_{\text {svgn,EUOther }}$, $\tau_{\text {svgn }, U S}, \tau_{\text {svgn,USBanks }}, \tau_{\text {svgn,USOther }}$, and from the VIM of the second subgroup (pc-macro) of the six country-specific macro fundamentals, Debt/GDP, exports/GDP ratio, GDP growth, industrial production, inflation, unemployment rate. The two principal components are reported in Fig 6 and show interesting patterns over time. Specifically, we observe that contagion-based variables, summarized by pc-contagion, assumed an increasing importance starting from the third quarter of 2008 (the Lehman Brothers collapse) until the first quarter of 2011. In such a period, fundamental-based variables, summarized by pc-macro, assumed an opposite tendency, with a drop in importance during 2008 (around the collapse of Bears Stearns) and with moderate importance throughout the end of 2009. Afterwards, and specifically starting from 2010, importance grew progressively with a peak at the end of 2011, before showing a large drop in the second quarter of 2012 (a quarter before Draghi's speech on July 26, 2012), but quickly returned to high values, moving in tandem with 
contagion-based variables until the end of the year. Ultimately, both importance metrics showed a downtrend towards their median at the end of the period. These results, therefore, confirm a time-varying importance assumed by fundamentals, which became relevant with the Greek crisis and the contagion-based factors that:

- assumed a key importance with the Lehman Brothers collapse,

- achieved new emphasis with the Euro debt crisis erupted in 2010,

- exhibited a temporary setback during 2011, but,

- became relevant again with the same impact of fundamental variables starting from 2012, and,

- finally, flexed towards a median reverting level at the end of the period together with fundamental-based variables.

\subsection{Discussion}

The results presented in the previous sections need a thorough discussion on the underlying economic meaning, clarifying pros and cons of the proposed methodology, elucidating the fundamental caveats one should keep in mind when using the model as an Early Warning System to signal impending sovereign debt abnormalities.

4.2.1. Advantages of the Methodology. Accurately predicting sovereign defaults is a very challenging issue, and even for sophisticated models, predictions are usually inaccurate, as evidenced by the abundant empirical evidence (e.g. Eichengreen (2002)). What we learned from the recent sovereign debt crisis in Europe is that a clear understanding of the sovereign risk dynamics requires the modeling of structural relationships that interact in nonlinear and state-contingent ways.

As pointed out by Morris and Shin (2000), macroeconomic systems are complex and exhibit multiple equilibria, implying a nontrivial and time-varying sensitivity towards small perturbations. Moreover, Kamin (1999) reminds us that financial crises have important idiosyncrasies and commonalities, and thus economic reasons underlying crises can vary over time and across regions. Standard econometric techniques are usually unable to handle all these issues in a pragmatic way and implicitly assume sovereign defaults can be reduced to common data models in which data are generated by independent draws from predictor variables, parameters, and random noise. Under these assumptions, conclusions from the fitted models "are about the models' mechanism, and not about natures mechanism" (Breiman (2001b) ) and as such, they may be misleading.

The recursive partitioning proposed in our paper takes another philosophical approach to handle the issue, since sovereign risk predictions are assumed to be the output of a partly unknowable system, in which a set of variables are selected and combined in order to provide a better prediction, thereby offering a better explanation of the underlying mechanism.

The most appealing feature of the regression trees approach is because it uncovers general forms of nonlinearity providing a general non-parametric way of identifying endogenous multiple data regimes from a set of predictor variables (Durlauf and Johnson (1995)). In essence, the final nodes contain sovereign risk estimates, expressed as expected CDS level, conditional on all the variables selected by the specific risk path. The risk stratification is obtained by combining predictor variables in a pragmatic way with the objective to identify the best threshold values for providing the better binary split through which the prediction error of the response variable is minimized. In this perspective, the "main" objective function of the approach is largely the same as that of the canonical linear regression models, since both approaches point to minimizing the prediction error, but the way with which they proceed is different.

Regression trees assemble a sequence of binary splitting rules acting as a series of "red flags" that pinpoint risk zones in the form of Early Warning System by construction. And since they 
combine the variables by compounding one each other, they are inherently non-linear. Their inner non-linearity permits to detect endogenous spatial and time regimes. The final nodes can include specific countries and/or specific time periods whenever the data "decide" to take into account country and time effects. In other terms, regression trees by itself identify final partitions whose scrutiny can tell us whether those final nodes are de facto regimes in time and space. The analysis we run by exploring the node composition (see Online Appendix Fig.7, Fig.9 and Fig.11) proves indeed that sovereign risk in Europe denoted country and time clustering during the crisis period 2008-2013 (see section 4.1.5 $5^{1}$ ).

On the other hand, canonical regression approaches provide "reduced" representation of the relationship between the $Y$ (in our case the sovereign risk) and $X s$, pre-selected based on some a-priory theory, through linear combinations of covariances between $Y$ and $X$. Coefficient estimates are noisy abstractions that cannot be used directly to form an Early Warning System. And due to their intrinsic linearity, they usually fail to produce robust predictions. Moreover, improvements in the estimation process to take into account the non-linear relationships offered by the theory usually do not prove to be so effective. This is the case, for e.g., documented in Fuertes and Kalotychou (2006) who show that simple pooled logits provide better sovereign default forecasts than complex models that allow for unobserved, fixed or random, heterogeneity across countries.

4.2.2. Limitations and Caveats. However, regression trees are not free from some limitations. First, and most importantly, they are extremely sensitive to the dataset upon which the procedure is executed, showing potential instability of the estimation results even for small changes in the data (Breiman (2001a); Breiman (2001b)). Second, they assume that the covariates are i.i.d. within each region (node) and independent across regions, when autocorrelations and other latent dependencies could instead play a major role in panel data. To address the first issue, the random forest procedure adopted in our paper, while allowing to assess the importance of the leading indicators used to explain the dynamics of the sovereign CDS has been used also to check whether results from our tree were robust in terms of both final predictions and selected variables. Indeed, by running multiple trees on sub-samples of data and variables, random forests act as robustness check procedure then strengthening the estimation results. To handle the second issue, we check the tree structure through a sensitivity analysis in which regression trees were re-run by removing one country per time. We focus on the Euro Sovereign Risk Area, as the Greek Only Area is itself a "world apart" that our procedure identified as a unique tree partition. How would the results change if one drops by removing, in turn, one of the countries? Our analysis gives an answer to this question, by confirming the robustness of our results in terms of endogenous regimes identified by the tree and key variables. As a whole, when changing countries in our sample, the risk stratification maintains quite the same general architecture in terms of selected indicators and splitting rules. The five trees obtained by excluding one country (see the Online Appendix Fig.15| Fig.20), confirm the role played by the Debt/GDP and the unemployment rate as key variables in splitting between low and high risk zones. The corresponding thresholds are almost the same, as they maintain the same values or show very limited changes. Only when removing Italy, we observe a change in Debt/GDP whose threshold becomes 0.937 in splitting between low and high risk, while instead it is fixed at 1.96-1.99 for other trees. Another change is within the trees excluding Portugal and excluding Ireland, where exports/GDP is placed after Debt/GDP and unemployment rate. Also regarding contagion-based indicators, we confirm the robustness of our results since they are placed again after the top splits to better discriminate risky nodes 1 . The final caveat we discuss refers to the seemingly static nature of the tree. Splits and thresholds are fixed within the structure and this might be viewed as constant parameters over time. Under these circumstances,

\footnotetext{
${ }^{1}$ For e.g. when we comment the high risk zone for the Euro Sovereign Risk Area and observe the time varying composition of the nodes.

${ }^{1}$ By confronting the five trees with the original one, we observe a little change between the Kendalls $\tau$ with Euro Other Financials and the Kendalls $\tau$ with Euro Banks, which is selected by the trees excluding Ireland and excluding Spain.
} 
we could be skeptical about the model when discriminating the risk zones in non-crisis periods based on splitting rules estimated using data of crisis periods. As is obvious, to avoid this potential drawback, regression trees should be computed based on data related to both crisis and non-crisis periods, as we did in our paper. As discussed, regression trees are inherently non-linear and detect endogenous regimes through their partitions. As such, non-crisis periods will be detected based on specific variables with corresponding thresholds that matter for those periods, while for crisis periods other variables or other thresholds (of the same variables) will be detected thereby stratifying the risk differently than the risk partitioning valid in tranquil times. This is exactly what happens in our regression tree we commented in terms of the time-varying composition of the final nodes. Therefore, if the reader is asking whether having low unemployment coupled with low Debt/GDP is enough to be in the safe zone, the answer is "yes" and regards all the Eurozone countries. This is what the data told us, but of course, we cannot use this rule forever, and we need to re-estimate the tree structure whenever new data are available. In this way, the seemingly static nature of the tree becomes dynamic. Again, notice the thresholds are "extreme values" of risk paths boundaries given by key variables: the selected variables include information also on other (not-selected) variables and within nodes means (and medians) should be scrutinized to better understand all facets of the risk nodes. The heatmaps we used in our analysis is a simple and effective way to do this.

\subsection{Post Quantitative Easing Period}

4.3.1. Forecasting Accuracy. In this section, the exercise we run concerns the out-of-sample analysis over the post-Quantitative Analysis period using the model estimated in the crisis period 2008-2013. In doing this we excluded Greece, as the CDS spreads remained into an upfront status until March 3, 2017. Therefore, we use the Euro Sovereign Risk Area partition (see Section 4.1.5) as our benchmark model to produce forecasts out of the estimation sample. We split the entire period between crisis period and post-Quantitative Easing (QE) period by choosing October 2013 as the cutoff date. The reason is because our objective is also to inspect what happened after QE measures were implemented, as the implications and the efficacy of the QE are examined from different perspectives by a lot of studies (we discuss later these studies alongside with our findings. Indeed on October 2013, the Single Supervisory Mechanism (SSM) was enacted through two regulations:

- The Council of the European Union formally approved on October 15, 2013 regulations creating the Single Supervisory Mechanism (SSM) for the oversight of banks and other credit institutions, thus establishing one of the main elements of Europes banking union.

- Afterwards, on October 22, 2013, we had the first formal step for establishing the European Banking Authority (EBA)2.

Following the same procedure used to assess the in-sample robustness, here we check the forecasting accuracy of our model relative to that shown by the panel model competitors (OLS pooled model; panel model with country fixed effects; panel model with country and time fixed effects). Such exercise encloses fundamental policy implications as it gives "food for thought" about a possible early warning system for impending sovereign risk abnormalities to be used in order to select adequate policy measures of prevention and mitigation. We discuss the point in the next section when comparing crisis with post-crisis periods.

Computationally, the reliability of our regression tree relative to the panel model competitors is assessed relying on both parametric and non-parametric diagnostics. Indeed, the significant reduction in the sovereign CDS spreads occurred in the post-QE leads to overestimate the CDS levels using models estimated over the crisis period. On average, and excluding Greece, CDS spreads

\footnotetext{
${ }^{1}$ Council Regulation (EU) No 1024/2013.

${ }^{2}$ Regulation (EU) No 1022/2013 of the European Parliament and of the Council on October 22, 2013.
} 
in the crisis period are in fact 163bps over the CDS spreads in the post-QE. For this reason, we measure the forecasting ability of the models using the common explained variance diagnostic $\left(R^{2}\right)$ together with the Kendall's $\tau$ between actual and estimated CDS. Being a measure of rank correlation and free from distributional assumptions, Kendall's $\tau$ is an appropriate diagnostic when dealing with non-linear, complex relationships and regime changes, as it is the case for the Euro sovereign CDS dynamics from crisis to post-crisis period. Using the Kendall's $\tau$, we measure the strength and direction of association that exists between expected and actual CDS instead of assessing the size of their average distance.

The results in Table 3 show an overperformance of the regression trees approach with an explained variance and Kendall's $\tau$ around 0.46 and 0.59, respectively. Only the OLS pooled model shows a good forecasting ability, while less than our model, with an explained variance of 0.31 and a Kendall's $\tau$ around 0.5. On the other hand, pooled models with fixed effects exhibit very poor diagnostics' values especially for the explained variance, which is 0.05 and 0.02 , for country and country and time fixed effects; the values for Kendall's $\tau$ are instead 0.39 (country fixed effects) and 0.26 (country and time fixed effects), then showing enough rank forecasting ability, while less than other models. In the same table, we also report the RMSE, which is explosive for panel models while contained and around 128bps for our model. Such a figure is consistent with the significant drop exhibited by the Euro sovereign CDS, excluding Greece, during the post-QE period: the arithmetic average of the estimation error is $-105 \mathrm{bps}$, which confirms the overestimation of the CDS spreads using the 2008-2013 period model. The size of this prediction error reflects relevant economic and, potentially, policy implications that we inspect in the following section.

To sum up, also in the out-of-sample analysis we provide evidence for the better predictive performance of regression trees approach compared with alternative panel models. The important question now we scrutinize concerns the main differences between 2008-2013 and 2013-2017 subperiods. Answering this question means understanding what changed into the CDS dynamics and which factors contributed to lowering the CDS spreads in the Eurozone.

\subsubsection{Comparing Crisis Period 2008-2013 and Post-QE Sovereign Risk Stratifica-} tions. The results of the out-of-sample analysis commented in the previous section while confirming the overall robustness of our procedure, they do not help explain what changed from 2008-2013 to post-QE period. What the analysis has shown is the model reliability in predicting the risk ranking based on macroeconomic variables and contagion-based factors. However, the substantial magnitude of the CDS prediction error arising from the analysis needs to be better understood. This is the objective of this section, in which: (1) we assess the higher spreads we would have had in the years 2013-2017 if the sovereign risk dynamics were the same as the ones observed during the period 2008-2013; (2) we compare and contrast the risk stratification in the crisis period 2008-2013 with the risk stratification of the post-QE years 2013-2017.

Post-QE Predictions and CDS Impacts. To handle the first issue, we actually refer to the prediction errors of the out-of-sample analysis as we project the Euro Sovereign Risk Area stratification estimated over the period 2008-2013 into the post-QE 2013-2017. In such a doing, we inspect what would have happened if the market reaction to country-specific macroeconomic variables and contagion effects was the same as we observed in the period over the years 2008-2013. And since QE interventions and macro-prudential policy measures have been implemented during the inspected period $[1$, our analysis indirectly provides an estimation of the policy measures impact, in terms of the lowest level of CDS spreads, over the years 2013-2017.

To assess the CDS impact for each country of our dataset, from $01 / 10 / 2017$ to $05 / 23 / 2017$, we introduce the following metric (which corresponds to the country-specific out-of-sample Mean

1 https://www.ecb.europa.eu/pub/fsr/html/measures.en.html 
Error):

$$
\Lambda_{j}=\sum_{t=1}^{T}\left(Y_{j, t}-\widehat{Y}_{j, t}\right)^{1 / T}
$$

where $T$ is the length of the time period in days, $Y_{j, t}$ is the actual CDS spread at time $t$ for country $j$ and $\widehat{Y}_{j, t}$ is the CDS spread prediction at time $t$ for country $j$ obtained using the Euro Sovereign Risk Area partition.

Table 5 reports $\Lambda_{j}$ measure for all countries excluding Greece. On average, we estimate an impact on the CDS spreads approximately of -105bps in the period 2013-2017. Assuming the same sovereign risk sensitivity towards macroeconomic fundamentals and contagion-based factors as we had during the crisis period 2008-2013, we would have had on average higher spreads for all countries: 76bps for France and Germany versus actual 26bps and 11bps, respectively; 117bps versus 48bps for Ireland; 259bps versus 105bps for Italy; 266bps versus 187bps for Portugal; 284bps versus $72 \mathrm{bps}$ for Spain.

This finding is particularly interesting as it quantifies the impact on the CDS spread dynamics occurred in the post-crisis exerted by a changed sovereign risk sensitivity towards macroeconomic fundamentals and financial contagion. This leads to questioning the second related issue, namely which factors have most affected the dynamics of the Euro sovereign risk during the post-crisis.

\section{Crisis Period and Post-QE Risk Stratifications: A Comparative Analysis.}

Post-QE Risk Stratification. We stratify the sovereign risk over the post-QE from $01 / 10 / 2017$ to $05 / 23 / 2017$ period using the same procedure as in Section using data from $01 / 10 / 2017$ to 05/23/2017. The risk stratification we obtain is depicted in Fig.3. Also for the post-QE, we obtain a first major split between Greek Only Area, containing only Greece, and Euro Sovereign Risk Area, containing the other six countries (France, Germany, Ireland, Italy, Portugal, Spain). However, while in the crisis 2008-2013 period the discrimination between the two main macro-regions is based upon the $\tau_{G I I P S}$ indicator (the Kendall's $\tau$ with GIIPS's CDS; see Fig.2), in the post-QE period the first split is made by Debt/GDP ratio with a threshold value of $152.87 \%$. Moreover, looking at risk discrimination for Greek Only Area we have industrial production that splits between high risk (industrial production less than 95.35) and moderate risk (industrial production greater than 95.35): the corresponding CDS spread expectations are 14, 900 and 1,411bps, respectively. Having obtained only two final nodes for the Greek area, which reflects a low-risk discrimination, is not surprising as the prices for the sovereign CDS remained fixed at 14,904bps until March 2, 2017, next moving around an average value of 736bps until the end of the period.

Different and more interesting is the risk discrimination obtained with the Euro Sovereign Risk Area, which shows the following key features:

- Safe zone. The zone is identified again with low Debt/GDP ratio and low unemployment rate. Very interestingly, the corresponding threshold values are very close to the ones of the crisis period. Indeed, the zone is with Debt/GDP ratio less than $120.85 \%$ and unemployment rate less than $11.95 \%$ versus $119.6 \%$ and $11.75 \%$, respectively, we obtained for the crisis period. Not as in the case of 2008-2013, the safe zone in the post-QE period includes two final nodes, since a final split is made depending on the unemployment rate: values less than $5.8 \%$ identify extremely low risk (the expected CDS value is $11 \mathrm{bps}$ ) while values greater than the threshold (but less than 11.95\%) are always typical for the safe zone while exhibiting slightly higher risk level (the expected CDS value is 33bps). Of further interest is also the composition of these two nodes, with Germany populating the first node, and France together with Ireland from 06/02/2014 until the end of the period populating the second one. 
- Moderate risky zone. Debt/GDP ratio less than $120.80 \%$ and the high unemployment rate (greater than $11.95 \%$ ) lead to a moderate risky zone (the expected CDS value is $71 \mathrm{bps}$ ) including Spain and Ireland, who stayed in this node from 01/31/2014 to 05/30/2014.

- Risky Zone. High values (and greater than 120.85\%) for the Debt/GDP ratio denote a risky zone, which is further stratified in three different sub-zones: (1) low exports/GDP (less than $34.20 \%$ ) with expected CDS value of 105bps; (2) positive Euro banking contagion (Kendall's $\tau$ of sovereign CDS with the Euro Banks 5-yr CDS index, $\tau_{\text {svgn,EUBanks, }}$, greater than -0.0213) with expected CDS value of 168bps; (3) negative Euro banking contagion ( $\tau_{\text {svgn,EUBanks }}$ less than -0.0213 ) with substantial expected risk (303bps). The role played by exports/GDP is quite interesting, as it seems to contrast with the common view in macroeconomics for which higher exports are beneficial for a country. What the partition is telling us is that exports/GDP lower than 0.342 leads towards a relatively less risky node, compared with exports/GDP exceeding the threshold. Note, firstly, that we are still in a risky zone characterized by high Debt/GDP, no matter about the level of exports. However, going ahead with the risk stratification the seemingly puzzling result actually discloses a non-linear relationship between sovereign risk and exports/GDP. In more depth, while the common view is that high exports/GDP is expected to be beneficial for a sovereign, whenever indebtedness is substantial the relationship tends to be detrimental, maybe due to lower GDP which artificially elevates the ratio exports/GDP 1 . With this finding, we, therefore, prove how regression trees are effective in disentangling complex and non-linear relationships which are instead difficult to detect through traditional (panel data) regression models.

Main Differences between Crisis Period and Post-QE Risk Stratifications. By comparing the risk stratification of the crisis period 2008-2013 (Fig.2) with that of the post-QE period (Fig.3), we obtain two major findings. The first concerns the key role played by the Debt/GDP ratio and the unemployment rate in both sub-periods, which also maintained fairly the same risk thresholds. As noted above, this finding is relevant especially from a policy perspective, as it provides evidence for an unchanged sovereign risk sensitivity towards these two macroeconomic fundamentals. As a result, the strong decline in CDS level from 2013 cannot be ascribed to such indicators: the risk signal from showing a high level of Debt/GDP greater than around 120\% together with high level of unemployment rate greater than a value near $12 \%$ remained the same over the entire period 2008-2017.

The second major finding is about the substantial negative variations from crisis period 2008-2013 to post-QE shown by contagion-based factors. To better explore the point, we inspect variations occurred, (a) in macroeconomic and contagion-based variables and, (b) in their corresponding risk thresholds.

In more depth, we first compute the variation rates of the average values of all the indicators from 2008-2013 to 2013-2017 periods for each country. Figure 4 shows the average variation rates across countries, while the results are depicted in Figure 5. To better compare these numbers with the impact on CDS spread dynamics occurred in the post-QE, the figures report also the $\Lambda_{j}$ measures (white rectangles). As a whole (see Figure 4), these values show negative variations from $-73.91 \%$ to $-100 \%$ for contagion-based factors, while macroeconomic variables show positive variation rates, except for GDP growth, with more contained values: inflation 1.86\%, industrial production $4.75 \%$, unemployment rate $4.03 \%$, debt/GDP $17.67 \%$, GDP growth $-0.99 \%$, exports/GDP $19.93 \%$. Such

\footnotetext{
${ }^{1}$ To confirm this conjecture, for the observations falling within the final nodes with expected CDS levels of 105,303 , $168 \mathrm{bps}$, we regressed the daily CDS onto exports/GDP, exports/GDP $\times D$, while controlling for the GDP growth and with $D$ a dummy, which takes the value of 1 when exports/GDP is greater than 0.342 , and 0 otherwise. With an $\bar{R}^{2}$ of 0.484 , the coefficient estimates (all statistically significant at 0.001 level) were: (1) -406.779 for exports/GDP; (2) 315.578 for exports/GDP $\times$ D; (3) 1267.441 for GDP growth. Hence, the positive sign for exports/GDP $\times D$ confirms the conjectured about the non-linear relationship.
} 
a big picture is virtually the same when observing the variation rates in every country (see Figure 5), then confirming the strong reduction of contagion-based factors in the post-QE period.

We next explored the variations occurred in the risk thresholds between the two sub-periods. To do this, we forced the regression tree grown over the post-QE to use the same indicators selected by the regression tree of the crisis period 2008-2013 (Fig,2). Analytically, we run the algorithm using one variable at a time constraining the procedure with two final nodes, thereby obtaining only one risk threshold per variable (splitting between low and high risk). In this way, we can compute the change occurred in the risk thresholds from crisis to post-QE period shedding light on the changes of the risk sensitivity exhibited by the leading indicators. The results are reported in table 5. For each variable of the 2008-2013 crisis-period risk stratification (Fig 2), we show the original threshold (crisis period) with that obtained through the constrained tree partition over the years 2013-2017. Contagion-based factors show on average a negative variation near to $-90 \%$ while changes in macroeconomic factor thresholds are negligible and close to $-1 \%$. Moreover, by observing the changes of the single thresholds, we confirm the same picture arising from the variations in the average values of single indicators (Figure 4), as the magnitudes and the sign of single variations are very close one each other pointing to the substantial decline in contagion-based factors as well as in their corresponding risk thresholds.

As with many unconventional central banks operations ${ }^{1}$ in recent years, it's still an open debate the effects of these policies. The ECB has publicly stated that these policies reduce redenomination risk, and, financial market "dysfunctionality", and, most importantly, the ECBs policies may have reduced the default risk component of GIIPS sovereign yields. Kräussl et al. (2016) note that the asset repurchases undertaken within the SMP in 2010-2011 had a substantial yield reduction impact, also contributing to lowering bond yield volatility and the extreme tail behavior of yield changes with substantial long-run effects, as also shown empirically by Eser and Schwaab (2016), who showed that the SMP brought large changes in bond yields upon purchase. Also, Altavilla et al. (2016) examined the impact of OMT on the government bond yields and found statistically significant and economical effects on credit and, in real activity in Italy and Spain. In the case of the core countries, France and Germany, some relatively limited spillovers were detected. The study of De Pooter et al. (2018) suggested that the SMP affected bond yields primarily through a reduction in the illiquidity premium in yields, using both bond yields and CDS spreads. Additionally, Krishnamurthy et al. (2018) compared the three ECB policies on sovereign bond yields in GIIPS countries and they found that the SMP and OMT were effective at reducing sovereign yields. Trebesch and Zettelmeyer (2018) explicitly refer to the Greek bonds, highlighting the impact on the short and medium maturity bonds, and a smaller impact on the CDS market. Our finding is in line with these studies and adds a novel result with significant policy implications, as we conjecture an impact of ECB interventions also in terms of reduced sovereign risk contagion, which has massively driven the general downturn of the CDS spreads in the Eurozone during the period 2013-2017. While these findings cannot show a direct connection between policy measures and impacts on CDS spreads, they contribute to quantifying what would have happened if the market reaction was the same as in the crisis period 2008-2013, also identifying which factors have mostly contributed with the lowering of the CDS spreads.

\section{Conclusions}

In this paper we propose a novel machine learning approach to identify sovereign risk zones. In a first step, we explore the cross-dynamics of sovereign CDS in terms of time-changing contagion measures based on copulas. In a second step, these measures are assembled together with countryspecific fundamentals, thereby identifying the leading indicators with corresponding red flags, which

\footnotetext{
${ }^{1}$ See for example, ECBs Executive Board Members Benoît Coeuré speech on September 2, 2013, http://www.ecb.europa.eu/ press/key/date/2013/html/sp130902.en.html
} 
are used to stratify sovereign risk in different risk regimes. Using data on Greek, Irish, Italian, Portuguese, Spanish, French and German sovereign CDS over the period 2008-2017, our empirical analysis provides important findings on the origin and the dynamics of sovereign risk during and after the Euro sovereign debt crisis erupted in 2010.

During the crisis period 2008-2013, we find that Greece is a "world apart" from July 2011, when the country started showing very low dependencies with other peripheral Euro countries with very high levels of CDS spreads mapped onto extremely high values for the unemployment rate and the Debt/GDP ratio. Sovereign risk can be mapped within three main risk zones based on contagion and country-specific fundamentals:

- a safe zone, characterised by low unemployment rate (less than 11.75\%) and moderate public indebtedness relative to GDP (Debt/GDP ratio < 119.6\%);

- a risky zone with high unemployment rate, or with low unemployment rate coupled with high Debt/GDP ratio;

- a high risk zone, where high unemployment rate (greater than $11.75 \%$ ) moves together with high Debt/GDP ratio (greater than 93.65\%) and significant sovereign dependency.

In such a risk stratification, macroeconomic fundamentals played a major role during the Greek crisis, while contagion-based factors became critical close to the collapse of Lehman Brothers.

In the sub-period 2013-2017, Greece continued to be a "world apart" again showing very high levels of CDS spreads mainly because of high Debt/GDP ratio. On the other side, the sovereign risk in Europe became less stratified and essentially based on macroeconomic fundamentals: (1) the safe zone is identified again with low Debt/GDP ratio and low unemployment rate showing threshold values very close to the ones of the crisis period 2008-2013 (Debt/GDP ratio less than $120.85 \%$ and unemployment rate less than 11.95\%); (2) High Debt/GDP ratio (less than 120.80\%) and high unemployment rate (greater than 11.95\%) lead to a moderate risky zone; (3) risky zone is identified with very high values (and greater than 120.85\%) for the Debt/GDP ratio.

Such a risk stratification compared with the one of the crisis period 2008-2013, while proving that the Debt/GDP ratio and the unemployment rate played a key role in both sub-periods also maintaining substantially the same risk thresholds leads to conclude that the strong decline in CDS level shown from 2013 onward cannot be ascribed to a changed market sensitivity towards macroeconomic variables. Differently, contagion-based factors shown substantial negative variations both in their values and corresponding risk thresholds, so much so that in an out-of-sample exercise over the sub-period 2013-2017, on average the price of sovereign credit risk for all the countries excluding Greece would have been about 101 basis point over the actual CDS spreads exhibited in the post-Quantitative Easing period, if the market reaction to country-specific macroeconomic variables and contagion effects was the same as in the period 2008-2013. Based on our findings, such an impact can be attributed to Quantitative Easing interventions and macro-prudential policy measures which contained contagion effects then reflecting on lower CDS spreads.

Finally, in terms of statistical reliability, we have found that for the data we have analysed, regression trees provide better predictive out-of-sample performance compared with alternative panel (model based) competitors. 


\section{References}

Acharya, V. V., Pedersen, L. H., Philippon, T. and Richardson, M. P., May 2010. Measuring Systemic Risk. AFA 2011 Denver Meetings Paper. Available at SSRN: http://ssrn. com/abstract=1573171 or http://dx.doi.org/10.2139/ssrn.1573171.

Acharya, V., Drechsler, I. and Schnabl, P., 2014. A Pyrrhic Victory? Bank Bailouts and Sovereign Credit Risk, Journal of Finance, 69, 2689-2739.

Acharya, V., Engle, R. and Richardson, M., 2012. Capital Shortfall: A New Approach to Ranking and Regulating Systemic Risks, American Economic Review, 102, 59-64.

Adrian, T. and Brunnermeier, M. K., CoVaR, September 2011. FRB of New York Staff Report No. 348. Available at SSRN: http://ssrn. com/abstract=1269446 or http://dx.doi.org/10.2139/ssrn.1269446.

Ait-Sahalia, Y., Laeven, R.J. A. and Pelizzon, L., 2014. Mutual Excitation in Eurozone sovereign CDS. Journal of Econometrics, 183, 151-167.

Aizenman, J., Hutchison, M. and Jinjarak, Y., 2013. What is the risk of European Sovereign Debt Defaults? Fiscal Space, CDS Spreads and Market Pricing of Risk. Journal of International Money \& Finance, 34, $37-59$.

Altavilla, Carlo, Giann6one, Domenico, and Michele Lenzaa, 2016. The Financial and Macroeconomic Effects of the OMT Announcements. International Journal of Central Banking,

Alter, A. and Schuler, Y. S., 2012. Credit Spread Interdependencies of European States and Banks During the Financial Crisis. Journal of Banking \& Finance, 36, 3444-3468.

Ang, A. and Longstaff, F. A., 2013. Systemic Sovereign Credit Risk: Lessons from the U.S. and Europe. Journal of Monetary Economics, 60, 493-510.

Arakelian, V. and Dellaportas P., 2012. Contagion Determination via Copula and Volatility Threshold Models. Quantitative Finance, 12, 295-310.

Arghyrou, M. G. and Kontonikas, A., 2012. The EMU Sovereign-debt Crisis: Fundamentals, expectations and contagion. Journal of International Financial Markets, Institutions and Money, 22, 658-677.

Athey, Susan. The Impact of Machine Learning on Economics. The Economics of Artificial Intelligence: An Agenda forthcoming, University of Chicago Press, January 2018.

Augustin, P., Subrahmanyam, M. G., Tang, D. Y. and Qian Wang, S., 2014. Credit Default Swaps: A Survey, Foundations and Trends in Finance, 9, 1/2, 1-196.

Augustin, P. and Tedongap, R., 2016. Real economic shocks and sovereign credit risk. Journal of Financial and Quantitative Analysis, 51, 541-587.

Beber, A., Brandt, M.W., Luisi, M., 2015. Distilling the Macroeconomic News Flow. Journal of Financial Economics, 117, 489-507.

Beetsma, R., Giuliodori, M., de Jong, F. and Widijanto, D., 2013. Spread the News: The Impact of News on the European Sovereign Bond Market during the Crisis. Journal of International Money and Finance, 34, 83-101.

Beirne, J. and Fratzscher, M., 2013. The Pricing of Sovereign Risk and Contagion During the European Sovereign Debt Crisis. Journal of International Money and Finance, 34, 60-82.

Breiman, L., 2001a. Random Forests. Machine Learning, 45, 5-32.

Breiman, L., 2001b. Statistical Modelling: The Two Cultures. Statistical Science, , 16, 199-215.

Breiman, L., 2003. Random Forests Manual v4.0, Technical report, UC Berkeley.

Broto, C. and Perez-Quiros, G., 2015. Disentangling Contagion Among Sovereign CDS Spreads During the European Debt Crisis. Journal of Empirical Finance, 32, 165-179.

De Bruyckerea, V., Gerhardt, M., Schepens, G. and Vander Vennet, R., 2013. Bank/sovereign Risk Spillovers in the European Debt Crisis. Journal of Banking \& Finance, 37, 4793-4809.

Caceres, C., Guzzo, V. and Segoviano, M., 2010. Sovereign Spreads: Global Risk Aversion, Contagion or Fundamentals?, IMF Working Paper 10/120.

Caporin, M., Pelizzon, L., Ravazzolo, F. and Rigobon, R., 2018. Measuring Sovereign Contagion in Europe. Journal of Financial Stability, 34, 150-181.

Cerutti, E., Claessens, S., and Laeven, L., March 2015. The Use and Effectivness of Macroprudential Policies: New Evidence Prepared. IMF Working Paper, WP/15/16.

Claessens, S., 2015. An Overview of Macroprudential Policy Tools. Annual Review of Financial Economics, 7, 397-422.

Doshi, H., Jacobs, K., and Zurita, V., 2017. Economic and Financial Determinants of Credit Risk Premiums in the Sovereign CDS Market. Review of Asset Pricing, 7, 1, 43-80. 
Durlauf, S. and Johnson, P., 1995. Multiple Regimes and Cross-Country Growth Behaviour. Journal of Applied Econometrics, 10, 4, 365-384.

ECB, 2012. The euro-area sovereign CDS market. Quarterly report on the euro area, 11, 1, April 2012.

ECB, Monthly Bulletin, June 2014.

Eichengreen, B., 2002. Predicting and Preventing Financial Crises: Where Do We Stand? What Have We Learned?, Kiel Week annual conference, Kiel, Germany, 24 - 25 June 2002.

Eser, F. and B., Schwaab, 2016. Evaluating the impact of unconventional monetary policy measures: empirical evidence from the ECB's Securities Markets Programme. Journal of Financial Economics, 119, 1, 147-167.

Forbes, K. J. and Rigobon, R., 2002. No contagion, only interdependence: Measuring stock markets comovements, Journal of Finance, 57, 2223-2261.

Fuertes, A. and Kalotychou, E., 2006. Early Warning Systems for Sovereign Debt Crises: The Role of Heterogeneity. Computational Statistics and Data Analysis, 51, 2, 1420-1441.

Goldstein, M., The Asian Financial crises: causes, cures, and systemic implications, Institute for International Economics, 1998, Washington.

Gonzlez-Hermosillo, B. and Johnson, C. A., 2014. Transmission of Financial Stress in Europe: The Pivotal Role of Italy and Spain, But Not Greece, IMF Working Paper No. 14/76.

De Grauwe, P., Ji, Y., and Macchiarelli, C., 2017. Fundamentals versus market sentiments in the euro bond markets: Implications for QE. Systemic Risk Center Special Paper No 12, The London School of Economics and Political Science.

Hastie, T., Tibshirani, R. and Friedman, J., The Elements of Statistical Learning: Data Mining, Inference and Prediction, 2009, Springer.

Jasra, A., Stephens, D. A. and Holmes, C. C., 2007. On Population-Based Simulation for Static Inference. Statistics and Computing, 17, 263-279.

Kalbaskaa, A. and Gatkowski, M., 2012. Eurozone Sovereign Contagion: Evidence from the CDS Market (2005-2010). Journal of Economic Behavior and Organization, 8, 657-673.

Kamin, S., 1999. The Current International Financial Crisis: How Much Is New?, FED International Finance Discussion Papers, 636.

Kendall, M., 1938. A New Measure of Rank Correlation. Biometrika, 30, 81-89.

Kräussl, R., Lehnert, T. and Stefanova, D., 2016. The European sovereign debt crisis: What have we learned?, Journal of Empirical Finance, 38, 363-373.

Krishnamurthy, Arvind, Nagel, Stefan, and Vissing-Jorgensen, Annette. 2018. ECB Policies Involving Government Bond Purchases: Impact and Channels, Review of Finance, 22, 1, 144.

Ling, R., 1973. A computer generated aid for cluster analysis. Communications of the ACM 16, 355361.

Longstaff, F. A., Pan, J., Pedersen, L. H. and Singleton, K. J., 2011. How Sovereign Is Sovereign Credit Risk?. American Economic Journal: Macroeconomics, 3, 75-103.

De Luca, G., Rivieccio, G., and Zuccolotto, P., 2010. Combining Random Forest and Copula Functions: A Heuristic Approach for Selecting Assets from a Financial Crisis Perspective. Intelligent Systems in Accounting, Finance and Management, 17, 91-109.

Manasse, P. and Roubini, N., 2009. "Rules of Thumb" for Sovereign Debt Crises. Journal of International Economics, 78, 192-205.

Manzo, G. and Picca, A., January 2015. The Sovereign Nature of Systemic Risk . Available at SSRN: http: //ssrn. com/abstract=2524991.

Meine, C., Supper, H. and Weiß, G.N. F., 2016. Is tail risk priced in credit default swap premia?. Review of Finance, 20, 287-336.

Mink, M. and de Haan, J., 2013. Contagion During the Greek Sovereign Debt Crisis. Journal of International Money and Finance,34, 102-113.

Morris, S. and H.S. Shin, 2000. Rethinking Multiple Equilibria in Macroeconomic Modeling. NBER Macroeconomics Annual, 15, 139-161.

Mullainathan, Sendhil and Spiess, Jann, 2017. Machine Learning: An Applied Econometric Approach. Journal of Economic Perspectives, 31, 2, 87106.

Nelsen, R.B., 1999. An Introduction to Copulas, Lecture Notes in Statistics, 139, Springer, New York.

De Pooter, M., Martin, R., and Pruitt, S. 2018. The Liquidity Effects of Official Bond Market Intervention. Journal of Financial and Quantitative Analysis, 53, 1, 243-268. doi:10.1017/S0022109017000898

Reboredo, J. C. and Ugolini, A., 2015. Systemic Risk in European Sovereign Debt Markets: A CoVaR-copula Approach. Journal of International Money and Finance, 51, 214-244. 
Rodriguez, Juan Carlos, 2007. Measuring Financial Contagion: A Copula Approach. Journal of Empirical Finance, 14, 401-423.

Oehmke, Martin and Zawadowski, Adam, 2017. The Anatomy of the CDS Market. Review of Financial Studies, 30, 1, 80-119.

Pesaran, M.Hashem and Smith, Ron, 1995. The Role of Theory in Econometrics. Journal of Econometrics, 67, 1, 61-79.

De Santis, R. A., 2014. The Euro Area Sovereign Debt Crisis: Identifying Flight-to Liquidity and the Spillover Mechanisms. Journal of Empirical Finance, 26, 150-170.

Sneath, P.H. A., 1957. The Application of Computers to Taxonomy. Journal of General Microbiology, 17, 20126.

Savona, R. and Vezzoli, M., 2015. Fitting and Forecasting Sovereign Defaults using Multiple Risk Signals. Oxford Bulletin of Economics and Statistics, 77, 66-92.

Stamatopoulos, Theodoros V., Arvanitis, Stavros E. and Terzakis, Dimitris M.,2017. The risk of the sovereign debt default: the Eurozone crisis 20082013. Applied Economics, 49, 38, 3782-3796.

Trebesch, Christoph and Zettelmeyer, Jeromin, 2018. ECB Interventions in Distressed Sovereign Debt Markets: The Case of Greek Bonds, IMF Economic Review, 66, 2, 287332. 
Table 1. Panel Models Estimates: from 01/02/2008 to 09/30/2013. The table reports in-sample model's estimates for OLS Pooled Model, country fixed effects, and country and time fixed effects. Variables that are significant at the 1,5 and 10 percent significance level are denoted by ***,** and * respectively.

\begin{tabular}{|c|c|c|c|}
\hline & OLS Pooled Model & $\begin{array}{l}\text { Country fixed } \\
\text { effects }\end{array}$ & $\begin{array}{l}\text { Country and time } \\
\text { fixed effects }\end{array}$ \\
\hline constant & $-1256.622^{* * *}$ & & - \\
\hline$\overline{\tau_{\text {svgn,EUBanks }}}$ & $-1384.07^{* * *}$ & $-1301.5337^{* * *}$ & $2843.1342^{* * *}$ \\
\hline$\tau_{\text {svgn, EUOtherFin }}$ & $4389.848^{* * *}$ & $4073.0202^{* * *}$ & $-466.5977^{* *}$ \\
\hline$\tau_{\text {svgn,USBanks }}$ & 224.1004 & $-709.5543^{* * *}$ & $-3784.426^{* * *}$ \\
\hline$\tau_{\text {svgn,USOtherFin }}$ & $1727.226^{* * *}$ & $3214.9258^{* * *}$ & $4264.7796^{* * *}$ \\
\hline$\tau_{\text {svgn }, U S}$ & $2576.834^{* * *}$ & $2017.0763^{* * *}$ & $4598.1587^{* * *}$ \\
\hline$\tau_{G I I P S}$ & $-7009.983^{* * *}$ & $-7070.0049^{* * *}$ & $-7978.4296^{* * *}$ \\
\hline$\tau_{F r, G e r}$ & $-3557.811^{* * *}$ & -307.2506 & $-4709.5271^{* * *}$ \\
\hline$\tau_{\text {svgn,svgn }}$ & $6530.518^{* * *}$ & $4013.0956^{* * *}$ & $-5329.0082^{* * *}$ \\
\hline inflation & $-8366.087^{* * *}$ & -26.4247 & $-9599.6958^{* * *}$ \\
\hline exports/GDP & -73.23133 & 65.4385 & $-2602.2133^{* * *}$ \\
\hline GDP growth & $1911.54^{* * *}$ & $2008.7726^{* * *}$ & $2409.4169^{* * *}$ \\
\hline industrial production & -0.901241 & $20.9904^{* * *}$ & $33.1575^{* * *}$ \\
\hline unemployment rate & $9479.544^{* * *}$ & $28208.2789^{* * *}$ & $18079.3895^{* * *}$ \\
\hline debt/GDP & $1031.929^{* * *}$ & $-1214.3735^{* * *}$ & $-1218.8618^{* * *}$ \\
\hline Adjusted $R^{2}$ & 0.6252 & 0.5635 & 0.5486 \\
\hline F-statistic & 1233.502 & 955.383 & 1006.900 \\
\hline
\end{tabular}

Table 2. In-Sample robustness check: from 01/02/2008 to 09/30/2013. The table reports in-sample model diagnostics for regression tree and competing panel models: OLS Pooled Model; Country fixed effects; Country and time fixed effects.

\begin{tabular}{|l|c|c|c|c|}
\hline Regression Tree & $\begin{array}{c}\text { OLS Pooled } \\
\text { Model }\end{array}$ & $\begin{array}{c}\text { Country fixed } \\
\text { effects }\end{array}$ & $\begin{array}{c}\text { Country and time } \\
\text { fixed effects }\end{array}$ \\
\hline$R^{2}$ & 0.9369 & 0.6257 & 0.5644 & 0.6151 \\
\hline RMSE & 527.7152 & 1072.4752 & 1528.6427 & 1371.7483 \\
\hline MSE & $278,483.28$ & $1,150,202.98$ & $2,336,748.50$ & $1,881,693.41$ \\
\hline
\end{tabular}

Table 3. Out-of-sample robustness check: from 10/01/2013 to 05/23/2017. The table reports out-of-sample model diagnostics for our model (regression tree) and panel model competitors. *** denotes Kendall's $\tau$ significant at 1 percent level.

\begin{tabular}{|l|c|c|c|c|}
\hline & Regression Tree & $\begin{array}{c}\text { OLS Pooled } \\
\text { Model }\end{array}$ & $\begin{array}{c}\text { Country fixed } \\
\text { effects }\end{array}$ & $\begin{array}{c}\text { Country and } \\
\text { time fixed effects }\end{array}$ \\
\hline$R^{2}$ & 0.4612 & 0.3061 & 0.0481 & 0.0206 \\
\hline Kendall's $\tau$ & $0.5933^{* * *}$ & $0.4993^{* * *}$ & $0.3853^{* * *}$ & $0.2623^{* * *}$ \\
\hline RMSE & 127.91 & $227,537.27$ & $256,682.57$ & $128,050.65$ \\
\hline MSE & $16,361.76$ & $5.18 \mathrm{E}+10$ & $6.59 \mathrm{E}+10$ & $1.64 \mathrm{E}+10$ \\
\hline
\end{tabular}

Table 4. Post-Quantitative Easing Predictions and CDS Impacts. The table reports for each country the CDS impacts $\Lambda$ (eq. 5), the average values of the actual CDS spreads and the average values of the predicted CDS spreads over the post-QE period from 10/01/2013 to $05 / 23 / 2017$. Values are in bps.

\begin{tabular}{|l|c|c|c|}
\hline Country & $\Lambda$ & Average actual CDS spreads & Average predicted CDS spreads \\
\hline France & -50 & 26 & 76 \\
\hline Germany & -65 & 11 & 76 \\
\hline Ireland & -69 & 48 & 117 \\
\hline Italy & -153 & 105 & 259 \\
\hline Portugal & -80 & 187 & 266 \\
\hline Spain & -213 & 72 & 284 \\
\hline \hline Average & -105 & 75 & 180 \\
\hline
\end{tabular}


Table 5. Risk Thresholds Variations. The table reportshttps://www.overleaf.com/6129484122npxybmhhdyyz the risk thresholds of the Euro Sovereign Risk Area partition for the crisis period 2008-2013 (column '2008-2013'), see fig. 22], the risk thresholds over the post-crisis (column 'Post-QE') period of the same battery of the leading
indicators obtained by running the regression tree algorithm using one variable at a time and forcing the risk fig. 2 , the risk thresholds over the post-crisis (column 'Post-QE') period of the same battery of the leading
indicators obtained by running the regression tree algorithm using one variable at a time and forcing the risk partition to come up with two final nodes. Column 'Variation' reports changes from 2008-2013 to post-QE.
Macroeconomic factors (Panel B) are in percent form and variations are computed as $\frac{x_{P o s t-Q E}-x_{2008-2013}}{x_{2008-2013}}$ for all partition to come up with two final nodes. Column 'Variation' reports changes from 2008-2013 to post-QE.
Macroeconomic factors (Panel B) are in percent form and variations are computed as $\frac{x_{P o s t-Q E}-x_{2008-2013}}{x_{2008-2013}}$ for all indicators excluding inflation: being computed as rate of change from period to period, the corresponding risk threshold variation is assessed as $x_{P o s t-Q E}-x_{2008-2013}$.

threshold variation is assessed as $x_{P o s t-Q E}-x_{2008-2013}$
\begin{tabular}{|l|c|c|c|}
\hline & $\mathbf{2 0 0 8 - 2 0 1 3}$ & Post-QE & Variation \\
\hline Panel A: contagion-based factors & & & $-107.152 \%$ \\
\hline$\tau_{\text {svgn, EUOtherFin }}$ & 0.3546 & -0.0254 & $-72.847 \%$ \\
\hline$\tau_{\text {GIIPS }}$ & 0.4924 & 0.1337 & $-96.965 \%$ \\
\hline$\tau_{\text {svgn, svgn }}$ & 0.4872 & 0.0148 & $-81.906 \%$ \\
\hline$\tau_{\text {svgn, } S}$ & 0.0871 & 0.0158 & $-89.718 \%$ \\
\hline Average & & & $1.045 \%$ \\
\hline Panel B: macroeconomic factors & & & $1.702 \%$ \\
\hline Debt/GDP & 119.6000 & 120.8500 & $-0.014 \%$ \\
\hline unemployment rate & 11.7500 & 11.9500 & $0.911 \%$ \\
\hline inflation & 0.0315 & 0.0177 & \\
\hline Average & & & \\
\hline
\end{tabular}
(20)

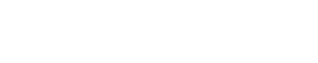

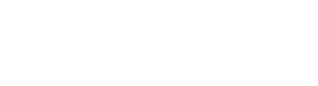


용

웄

8.

융

음

음

5

항

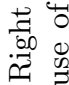

승 㐘

को

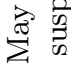

$\circ$ 잉

$\stackrel{\infty}{\circ}$

กั

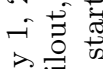

तై

을

สี

로

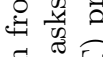

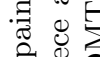

की ญ्र

䒕

त्ञ

융

䒕

$\because$ ต

तี ซี

芯泀泀

$\ddot{\sim}$

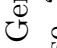

है

厌

깅

㐘志

范

की $D$

讯

它苍

है

.

需

क สี

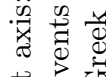

$\rightleftarrows$ वे

$\stackrel{0}{\ominus} \ddot{0}$

- $\sum^{\frac{\sigma}{2}}$

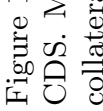




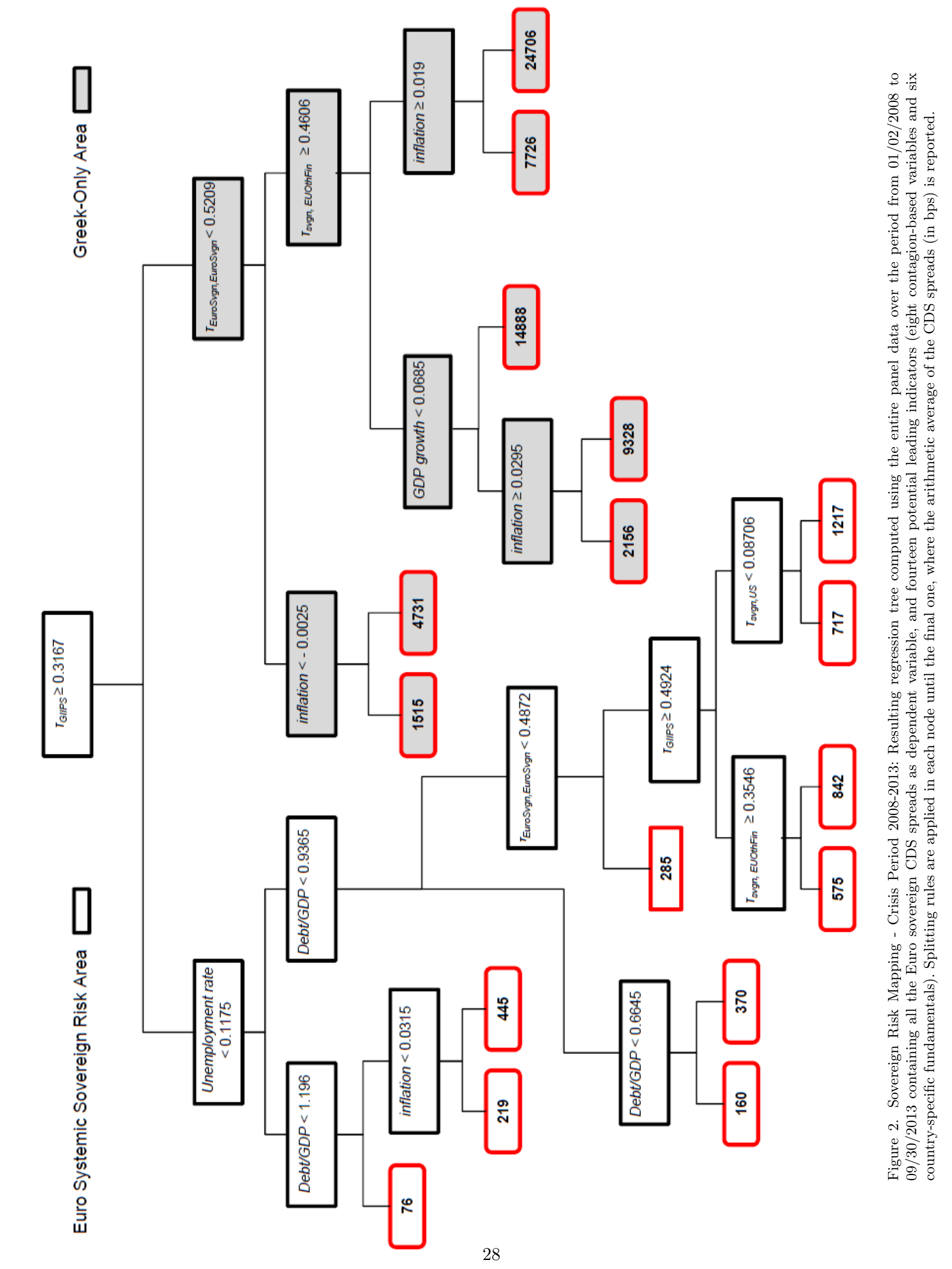




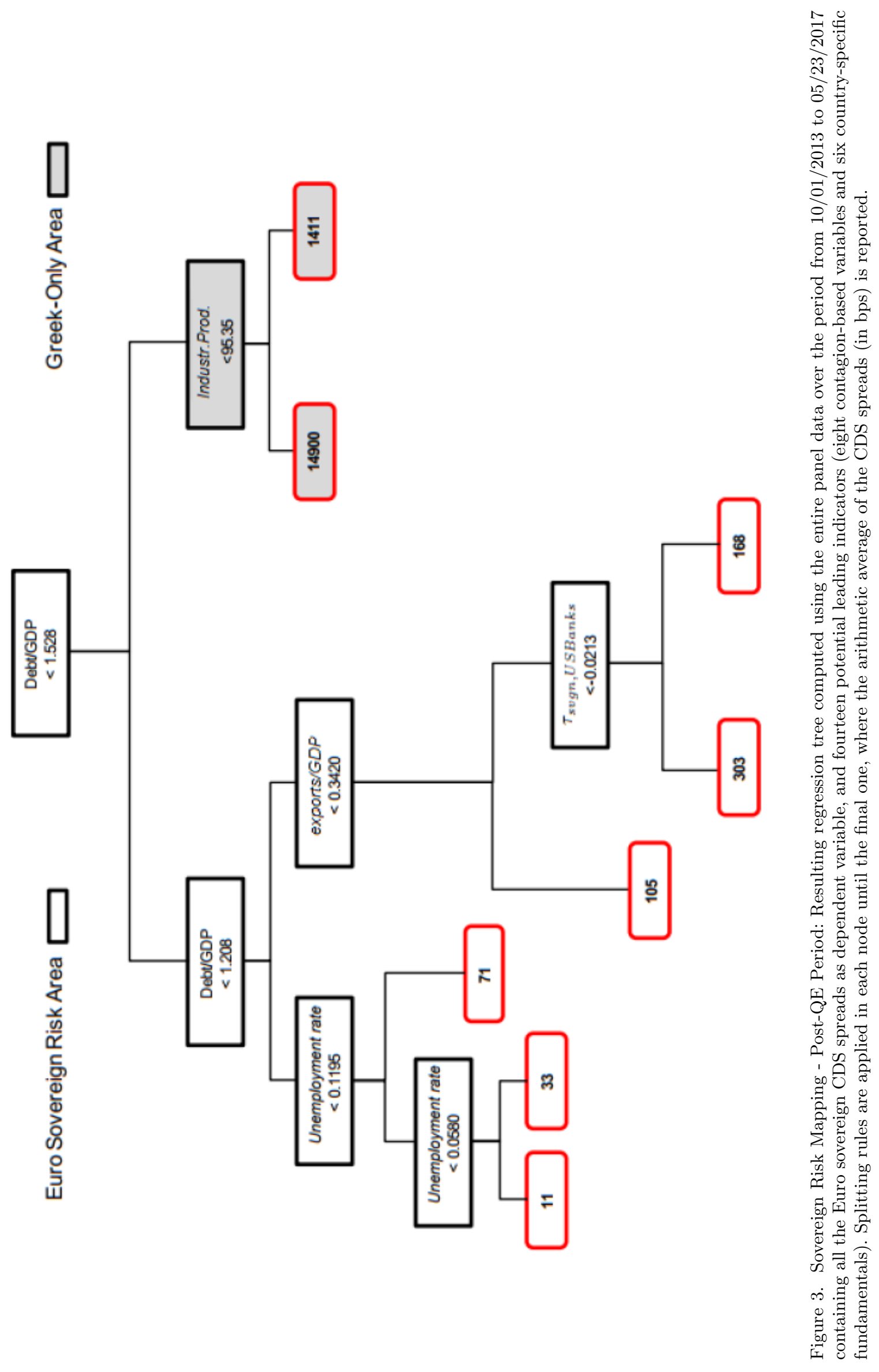




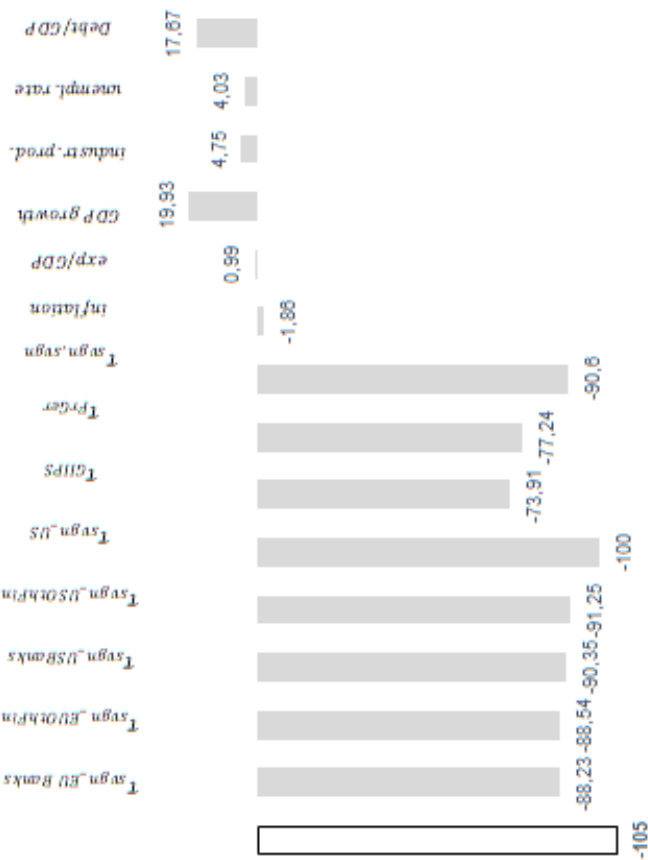

+

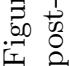




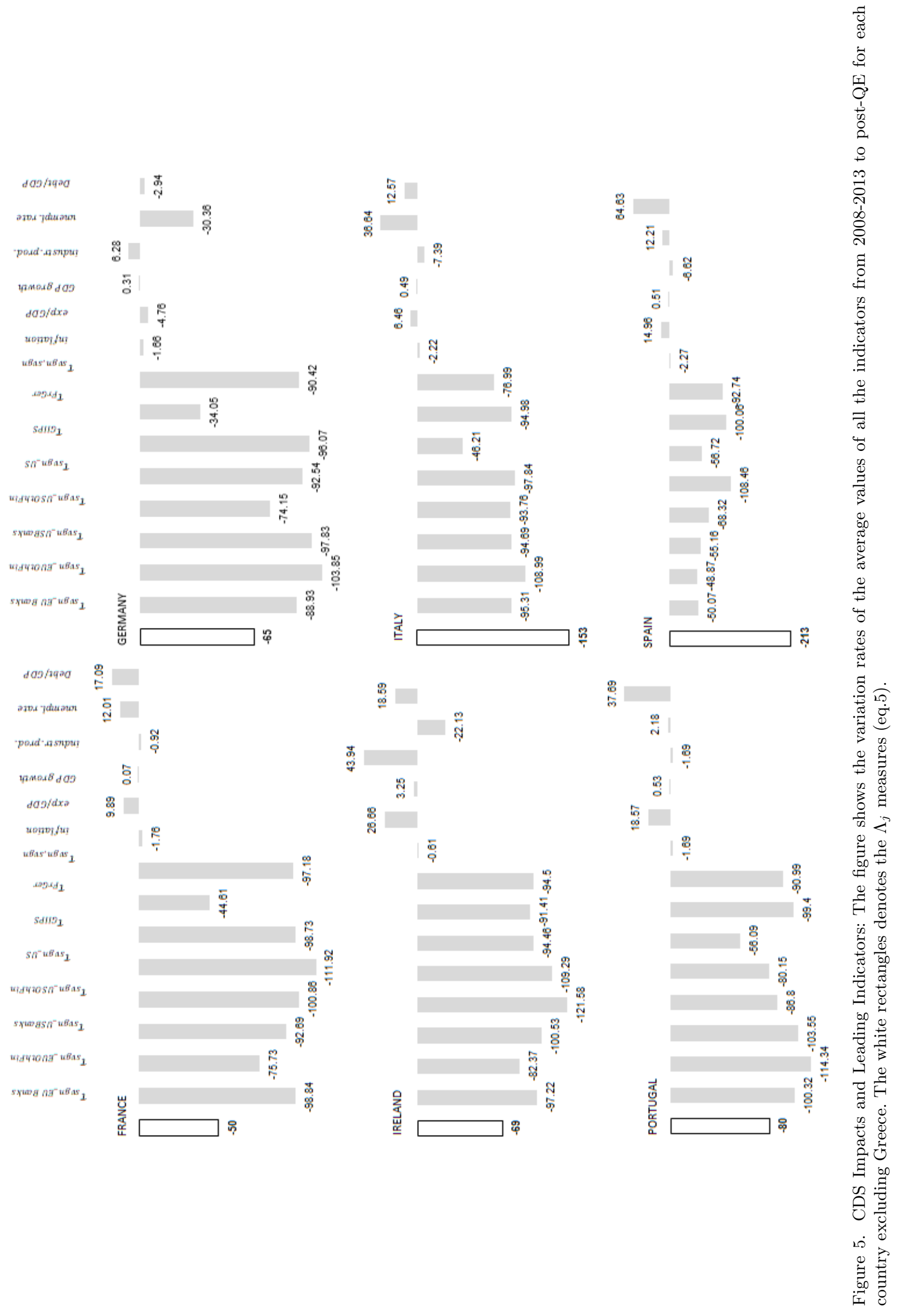



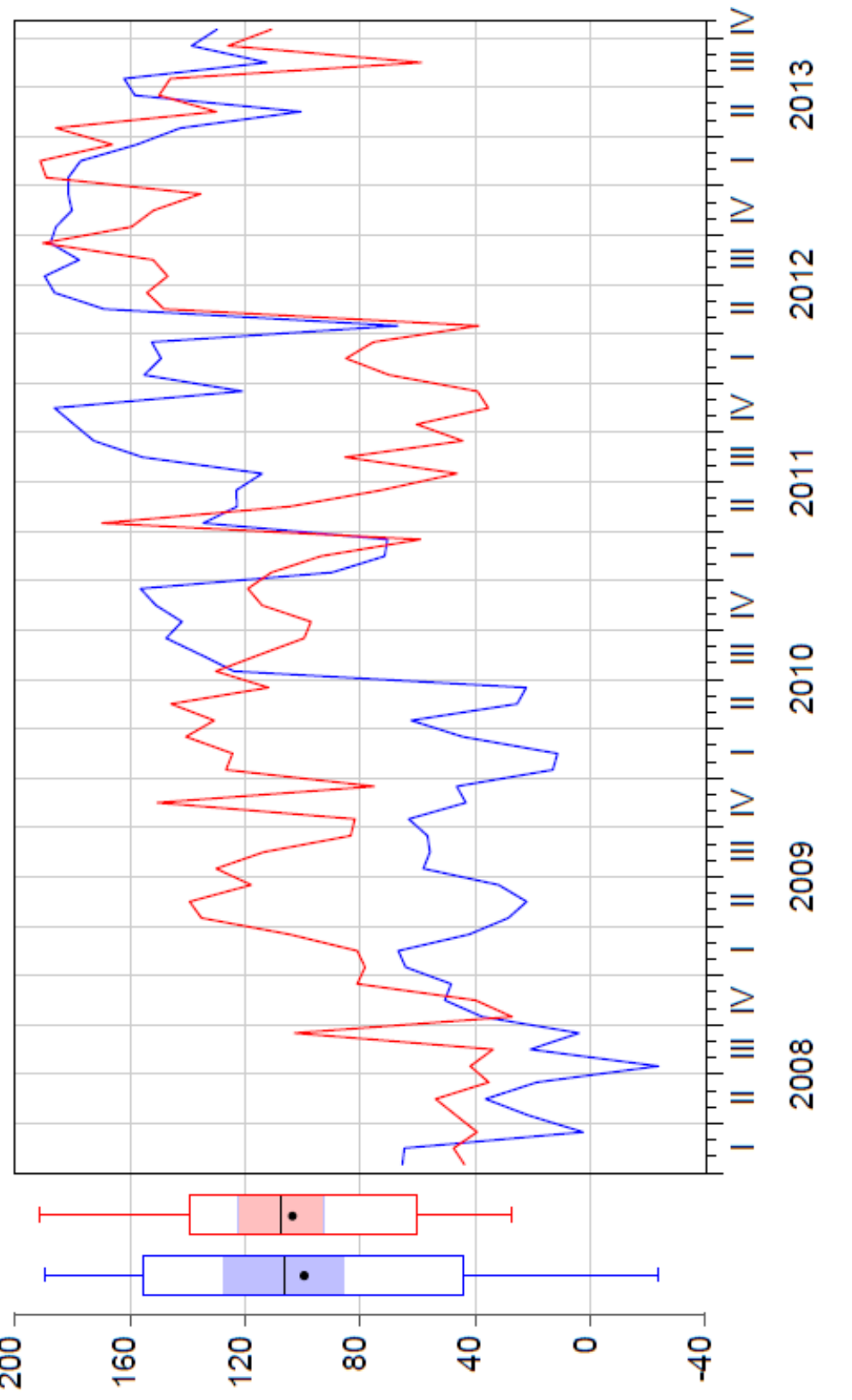